\title{
Head Direction Cell Activity in Mice: Robust Directional Signal Depends on Intact Otolith Organs
}

\author{
Ryan M. Yoder and Jeffrey S. Taube \\ Department of Psychological and Brain Sciences, Center for Cognitive Neuroscience, Dartmouth College, Hanover, New Hampshire 03755
}

\begin{abstract}
The head direction (HD) cell signal is a representation of an animal's perceived directional heading with respect to its environment. This signal appears to originate in the vestibular system, which includes the semicircular canals and otolith organs. Preliminary studies indicate the semicircular canals provide a necessary component of the HD signal, but involvement of otolithic information in the HD signal has not been tested. The present study was designed to determine the otolithic contribution to the HD signal, as well as to compare $\mathrm{HD}$ cell activity of mice with that of rats. HD cell activity in the anterodorsal thalamus was assessed in wild-type C57BL/6J and otoconiadeficient tilted mice during locomotion within a cylinder containing a prominent visual landmark. HD cell firing properties in C57BL/6J mice were generally similar to those in rats. However, in C57BL/6J mice, landmark rotation failed to demonstrate dominant control of the $\mathrm{HD}$ signal in $36 \%$ of the sessions. In darkness, directional firing became unstable during $42 \%$ of the sessions, but landmark control was not associated with HD signal stability in darkness. HD cells were identified in tilted mice, but directional firing properties were not as robust as those of C57BL/6J mice. Most HD cells in tilted mice were controlled by landmark rotation but showed substantial signal degradation across trials. These results support current models that suggest otolithic information is involved in the perception of directional heading. Furthermore, compared with rats, the HD signal in mice appears to be less reliably anchored to prominent environmental cues.
\end{abstract}

Key words: otolith organs; mouse; gravity; anterodorsal thalamic nucleus; navigation; head direction

\section{Introduction}

Accurate navigation depends, in part, on a neural representation of directional heading, which appears to be encoded by head direction (HD) cells located throughout Papez circuit (for review, see Sharp et al., 2001a; Taube, 2007). This HD signal provides a constantly updated representation of perceived orientation in the yaw plane, regardless of the animal's position within an environment. Generation of the HD signal depends on information from the vestibular labyrinth, because damage to the vestibular labyrinth, either permanent or temporary, disrupts the HD signal and causes spatial memory impairments (Stackman and Taube, 1997; Stackman and Herbert, 2002; Stackman et al., 2002; Wallace et al., 2002; Schautzer et al., 2003; Brandt et al., 2005). Within the vestibular labyrinth, the semicircular canals sense angular acceleration and the otolith organs sense linear acceleration, including static pitch/tilt relative to gravity (Tait and McNally, 1934; Adrian, 1943; Fernandez et al., 1972; Fernández and Goldberg, 1976a,b,c). Both systems appear to be necessary for accurate perception of rotation and translation because activation of the canals occurs with respect to a head-based reference frame and the otoliths are unable to distinguish between

Received Aug. 14, 2008; revised Dec. 16, 2008; accepted Dec. 17, 2008.

This work was supported by National Institutes of Health Grants NS053907, DC009318 (J.S.T.), and DC008481 (R.M.Y.). We thank Anton Khabbaz and Robert Stackman for technical discussions.

Correspondence should be addressed to Jeffrey S. Taube, Department of Psychological and Brain Sciences, Dartmouth College, 6207 Moore Hall, Hanover, NH 03755. E-mail: jeffrey.s.taube@dartmouth.edu.

DOI:10.1523/JNEUROSCI.1679-08.2009

Copyright $\odot 2009$ Society for Neuroscience $\quad$ 0270-6474/09/291061-16\$15.00/0 linear acceleration and static pitch or tilt (Angelaki et al., 1999; Angelaki and Dickman, 2003). Disambiguation of vestibular afferent information has been postulated to occur in the cerebellum, in which Purkinje cells encode purely translational movement (Yakusheva et al., 2007). Thus, signals from the semicircular canals and the otolith organs appear to provide critical components of the HD signal.

Recent experiments indicate that the HD signal specifically depends on intact semicircular canals, because the HD signal is disrupted after canal occlusion (Muir et al., 2004; Brown et al., 2006). These studies, however, did not address the possible contribution of otolith activity to the HD signal, which is suggested by the loss of direction-specific firing during behavioral manipulations that alter the otolith signal. For example, rats trained to traverse a three-dimensional track showed normal HD cell activity while on the floor and walls but showed a marked loss of direction-specific activity while locomoting in an inverted position (Calton and Taube, 2005). This disruption may occur because the HD signal depends on a familiar otolith signal, and otolithic representation of an inverted body position is usually unfamiliar to terrestrial animals. If neural signals originating in the otoliths are necessary components of the HD signal, then elimination of the otolith signal should disrupt the HD signal.

To determine otolithic involvement in HD signal generation, the present study assessed HD cell activity in animals lacking otolith signals. Most HD studies have been conducted in rats, but surgical ablation of the otolith organs in rats would likely cause collateral damage to the semicircular canals and confound inter- 
pretation of the results. We therefore used mutant mice lacking otoconia, as previous preliminary reports have indicated the presence of HD cells in the anterodorsal thalamus (ADN) of wildtype mice (Khabbaz et al., 2000; Khabbaz and Tank, 2004). Several strains of otoconia-deficient mice are available, and we chose tilted mice (Lane, 1986) because the only phenotypic mutation, complete otoconia agenesis, appears in nearly $100 \%$ of homozygotes (Ornitz et al., 1998). HD cell activity was recorded from the ADN of wild-type C57BL/6J mice for comparison with activity recorded from the $\mathrm{ADN}$ of tilted mice.

\section{Materials and Methods}

Subjects. All experimental procedures were approved by the Dartmouth College Institutional Animal Care and Use Committee. The present study included wild-type mice [C57BL/6J (The Jackson Laboratory); $20-33 \mathrm{~g} ; n=7$ males] and otoconia-deficient tilted mice homozygous for the Otop $1^{\text {tlt }}$ mutation, which are maintained in the C57BL/6J background strain [B6.CG-Otop ${ }^{t l t} /$ J (The Jackson Laboratory); $20-33$ g; $n=$ 4 males, 4 females]. All mice were group housed preoperatively and individually housed postoperatively within the same colony room. All mice received food and water ad libitum.

Before surgical and electrophysiological procedures, mice were screened for behavioral anomalies associated with otoconia agenesis as reported previously (Ornitz et al., 1998). Briefly, at $\geq 11$ weeks of age, mice were dropped from a height of $10 \mathrm{~cm}$ into a pool of water. C57BL/6J mice immediately resurfaced and swam in an upright position, whereas tilted mice rolled onto their backs and swam underwater in an inverted spiral manner. Tilted mice usually did not resurface, and rescue by the researcher was required to prevent drowning. All tilted mice included in the present study were unable to maintain an upright swimming posture. Several additional tilted mice were excluded from the study before electrophysiological assessment because of their intermediate swimming ability, characterized by an upright swimming posture punctuated by back flips and somersaults.

Electrodes. A miniature version of the multiple-electrode microdrive designed for rats (Kubie, 1984) was used. Each microdrive was constructed from $1025-\mu \mathrm{m}$ insulated nichrome wires (California Fine Wire) encased by a 26 gauge stainless steel cannula. Each wire contacted one gold pin of a modified 11-pin Augat connector. The finished electrode drive provides connections for 10 recording electrodes (tip impedance $\sim 2 \mathrm{M} \Omega$ ) and one ground connection. Dental acrylic was used to encase the cannula, wires, and connector and to hold the heads of three drive screws. Tips of the drive screws were threaded into custom-built plastic cuffs, which were later cemented to the skull. These cuffs provided a fixed base into which the screws were advanced to lower the electrodes into the brain.

Surgery. Mice were anesthetized with ketamine/xylazine (90 and 10 $\mathrm{mg} / \mathrm{kg}$, respectively) and positioned in a stereotaxic apparatus (David Kopf Instruments) with bregma and lambda in the same plane. The scalp was retracted, and a hole was drilled above the ADN. Additional holes were drilled in the frontal, parietal, and occipital bones into which jeweler's screws (Lomat Precision) were threaded. These screws were reinforced to the skull with a drop of superglue. The electrode bundle was sterilized and coated (except for the tips) with polyethylene glycol before being positioned dorsal to $\mathrm{ADN}(0.5 \mathrm{~mm}$ posterior, $0.70 \mathrm{~mm}$ lateral, 2.0 $\mathrm{mm}$ ventral to bregma). With the electrode bundle in position, the drive screw/cuff assemblies were fastened to the skull and jeweler's screws with Grip Cement (Dentsply International). The scalp was sutured around the electrode drive, and the animal was allowed to recover 1 week before recording. An implanted electrode drive is shown in supplemental Figure S1 (available at www.jneurosci.org as supplemental material). Buprenorphine $(0.015 \mathrm{mg} / \mathrm{kg})$ was administered as a postoperative analgesic.

Signal processing. During recording sessions, the electrical signal from each electrode was conducted to a 10-channel head stage containing a unity gain operational amplifier. A flexible 25-conductor cable connected the head stage to an overhead commutator. After the commutator, electrical signals were amplified (P5 series; Grass Instruments) and bandpass filtered $(300-10,000 \mathrm{~Hz})$ before auditory and visual display on

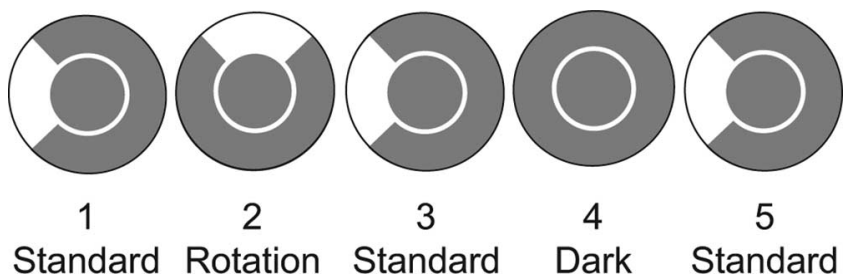

Figure 1. Schematic top view of the recording arena (with white cue card indicated by white band) and rotation protocol used to assess $\mathrm{HD}$ cells. Each $\mathrm{HD}$ cell was recorded during a standard session (1), followed by a rotation session in which the visual cue card was rotated $90^{\circ} \mathrm{CW}$ or CCW (2), a second standard session (3), a dark session with no visual cue card (4), and a final standard session (5).

a loudspeaker and oscilloscope (model 2214; Tektronix). A dual time and amplitude window discriminator (model DDIS-1; BAK Electronics) was used to isolate single-unit spikes from background noise and triggered an electrical pulse during spike detection.

An overhead color video camera (Sony XC-711) was used to monitor the animal's $\mathrm{HD}$ at $60 \mathrm{~Hz}$ by tracking the position of one red and one green light-emitting diode (LED) attached to the animal's head stage, separated by $11 \mathrm{~cm}$. Signals generated by the window discriminator at the occurrence of single-unit spikes and the concurrent LED positions were acquired by a computer [MacIntosh G4 (Apple Computers)] running Labview software (version 5.0; National Instruments). Data were analyzed with Labview, and graphs were generated with Microsoft Excel.

Apparatus. A small black cylinder consisting of a wooden platform (40 $\mathrm{cm}$ diameter) surrounded by a black wall $(40 \mathrm{~cm}$ height $)$ contained a white cue card that covered $\sim 90^{\circ}$ of the wall surface. For standard trials, the white cue card was centered at the 9:00 position as viewed by the camera. A black curtain extending from the ceiling to the floor surrounded the arena to discourage animals from using visual cues other than the white cue card. An overhead speaker controlled by a white noise generator was used to discourage the use of auditory cues. The wooden arena floor was cleaned with soap and water between sessions to discourage the use of olfactory cues.

Recording procedure. Mice were screened daily for HD cells as reported previously (Taube, 1995). Briefly, electrodes were connected to the head stage, and the mouse was placed in the arena. Each of the 10 channels was evaluated for single-unit activity with $>2: 1$ signal-to-noise $(\mathrm{S} / \mathrm{N})$ ratio. During visual or audible detection of single-unit spikes, the window discriminator was adjusted to isolate these spikes from background noise. For all cells, only records in which the cellular waveforms were well isolated from background noise throughout the recording session were included in analyses.

The occurrence of spikes was visually assessed for directional modulation, after which cell activity was recorded across several conditions using a protocol developed previously (Fig. 1). This procedure includes monitoring HD cell responses during five consecutive sessions: (1) standard ( $8 \mathrm{~min})$, white cue card is positioned in the standard position; (2) rotation $(8 \mathrm{~min})$, white cue card is rotated $90^{\circ}$ clockwise (CW) or counterclockwise (CCW) from the standard location; (3) standard (8 min), white cue card is returned to the standard location; (4) darkness (16 $\mathrm{min}$ ), white cue card is removed and the overhead lights are extinguished; and (5) standard ( $8 \mathrm{~min})$, white cue card is replaced at the standard location and lights are turned on. Before the beginning of each session, the mouse was placed in an opaque container and the experimenter slowly carried the animal around the outside of the arena in both directions while rotating the container to disorient the animal. For two cells in C57BL/6J mice, the recording procedure included additional rotation sessions, and the dark/no cue session was only $8 \mathrm{~min}$ in length, instead of 16 min. No differences in HD cell activity were observed between these mice and those that were assessed using the procedure described above. Therefore, data obtained during rotation and dark/no cue conditions from these cells were included in all analyses.

Note that, although the overhead lights were extinguished to eliminate the use of visual cues during session 4, the red and green tracking LEDs could have provided a small amount of ambient illumination within the 
arena. This illumination was presumably unusable for HD perception however, because the black featureless walls of the cylinder did not appear to provide any visual landmark information. This presumption is supported by the results reported here, which are consistent with previous findings with blindfolded rats (Goodridge et al., 1998).

Data analysis. HD was determined by calculation of the angle between the positions of the anterior (red) and posterior (green) LEDs within a $256 \times 256$ pixel field at $60 \mathrm{~Hz}$. HD during each $16.667 \mathrm{~ms}$ epoch was then sorted into $606^{\circ}$ bins. The average firing rate as a function of HD within a session was calculated by dividing the total number of spikes by the amount of time the HD was within the limits of each bin. Data from cells that appeared to exhibit an increased firing rate as a function of HD were subjected to Rayleigh's test (Batschelet, 1981) to determine whether firing occurred randomly or clustered in a particular direction. Although a significance criterion of $0.20 \leq r<0.40$ indicates directional modulation that is significantly different from a random distribution, these cells were not classified as HD cells because their tuning curves did not resemble classical tuning curves of HD cells found in rats. Therefore, we adopted a significance criterion of $r \geq 0.40$ for a cell to be considered an HD cell.

Additional cell discharge characteristics were derived from the raw data and triangular model, as reported previously (Taube et al., 1990a). For the triangular model, linear positive and negative slopes were manually fit to the raw data to form a triangle with the $x$-axis as base. From the triangular model, five characteristics of cell activity were calculated: (1) background firing rate (mean firing rate in all directions $18^{\circ}$ away from the $x$-intercept of each triangle leg); (2) peak triangular firing rate ( $y$ coordinate of the apex of the triangle); (3) triangular preferred firing direction ( $x$-coordinate of the apex of the triangle); (4) directional firing range (the difference, in degrees, between the $x$-coordinates of the base of triangle legs); and (5) asymmetry score (the left leg slope divided by the absolute value of the right leg slope). The $\mathrm{S} / \mathrm{N}$ ratio was computed as the peak firing rate divided by the background firing rate.

For comparison with data from the triangular model, observed peak firing rate and preferred direction were also calculated. A Gaussian curve was fit to the raw data, with the Gaussian mean corresponding to the preferred firing direction. A correlation coefficient was then calculated between a Gaussian curve and the raw data, as reported previously (Zhang, 1996).

The anticipatory time interval (ATI) was calculated for each HD cell using a time-shift analysis, as reported previously (Blair and Sharp, 1995). In the original study, cellular activity during angular head velocities (AHVs) $>90^{\circ} / \mathrm{s}$ were used for ATI analyses. However, because bidirectional sampling at $>90 \%$ s was insufficient for two C57BL/6J HD cells, this lower limit was reduced to $60 \%$ s. With this limit, all $24 \mathrm{C} 57 \mathrm{BL} / 6 \mathrm{~J} \mathrm{HD}$ cells were included in the analysis. For tilted mice, the $60 \% \mathrm{~s}$ lower limit allowed inclusion of eight HD cells (vs six HD cells with the $90 \%$ s limit). Although the mean ATI for C57BL/6J HD cells was not significantly different when using the $60 \%$ s versus $90 \%$ s velocity limit ( $p=0.968)$, it is important to note differences between our methodology and that of previous studies.

Directional information content (IC) was calculated for each cell as reported previously (Stackman and Taube, 1998): IC $=\sum p_{i}\left(\lambda_{i} / \lambda\right)$ $\log _{2}\left(\lambda_{i} / \lambda\right)$, where $p_{i}$ is the probability of the head pointing in the $i$ th bin, $\lambda_{i}$ is the firing rate when the head is pointed within the $i$ th bin, and $\lambda$ is the overall mean firing rate of the cell for all bins. An information content value of 0 indicates no relation between $\mathrm{HD}$ and firing rate, and a value $\geq 1$ indicates a strong relation between $\mathrm{HD}$ and firing rate. In cases in which multiple HD cells were recorded on the same electrode, directional IC scores were not calculated because $\lambda$ is potentially biased by the spikes of additional cell(s).

To determine the response of a cell to cue card rotations, the crosscorrelation between sessions 1 and 2 were calculated as described previously (Taube et al., 1990b). Briefly, the firing-rate/head-direction function for session 1 was shifted clockwise in $6^{\circ}$ steps, and the crosscorrelation between the curves was recalculated at each step. The angular shift of each cell was defined as the angle at which the cross-correlation was maximal. Previous studies indicate that, when multiple HD cells are simultaneously recorded, the preferred firing directions for all HD cells rotate in register (Taube et al., 1990b). Therefore, for recording sessions during which multiple HD cells were recorded, the average shift of the preferred directions for simultaneously recorded cells was used for statistical calculations.

A firing rate $\times \mathrm{HD} \times$ time analysis was used to plot preferred direction stability throughout a single session. This analysis calculates the average $\mathrm{HD}$ and firing rate for bins of 10 consecutive ( $1 / 60 \mathrm{~s}$ ) samples, for an effective temporal resolution of $1 / 6 \mathrm{~s}$. When the firing rate for any bin reaches $75 \%$ of the maximum firing rate for all bins within a session, an $\mathrm{HD} \times$ time point is generated. From the plots of cells that showed a constant preferred direction shift $<360^{\circ}$ throughout the recording session, a regression line was fit to the $\mathrm{HD} \times$ time points to quantify the preferred direction drift (degrees) over time (seconds). For plots that showed $>360^{\circ}$ of drift throughout the session, the plot was divided into time segments, each of which contained a single slope. The preferred direction drift for these cells was calculated as the mean absolute slope across all time segments. To quantify the drift for sessions in which the preferred direction shifted one direction for a portion of a session and then shifted the other direction for another portion of the session, we divided the sessions into primary and secondary portions that corresponded to the individual drifts. The absolute values of the CW and CCW drifts were then calculated, and the mean of these absolute values was used to define the drift of preferred direction for each cell.

The spike train of HD cells generally includes periods of low activity punctuated by periods of high activity that resemble bursts. Because the occurrence of bursts is determined by the animal's HD, the bursts of activity appear nonperiodic and of indefinite duration. Therefore, we developed a measure, referred to as the burst index, to represent the proportion of time during which a cell fired in high-frequency bursts or was inactive relative to the time during which action potentials occurred at a relatively constant rate. For this measure, spikes were sorted into $1 \mathrm{~s}$ bins from the beginning to the end of a recording session. The burst index was defined as follows:

$$
\text { Burst index }=\frac{(\# \text { of bins }>1.75 \overline{\mathrm{FR}})+(\# \text { of bins }<0.25 \overline{\mathrm{FR}})}{\# \text { of bins } \mathrm{Total}_{\mathrm{T}}},
$$

where $\overline{\mathrm{FR}}$ represents the mean firing rate over the entire session, and bins $_{\text {Total }}$ represents the total number of bins during the session. Burst index values can range between 0 and 1 , with a value of 0 indicating a firing rate that remains near the mean rate for the entire session and a value of 1.0 indicating the cell is bursty and either remains silent or fires near its maximal rate for the entire session.

For all analyses, means are reported along with SEM. Group comparisons were conducted on a personal computer with statistical software (Statview, version 5.0.1; SAS Institute).

Several terms are used in Results to describe HD cell properties. "Signal degradation" indicates that the HD cell provides a less robust representation of direction, as indicated by a reduced Rayleigh's $r$ value calculated from the tuning curve. "Stability" refers to the consistent firing of an HD cell in relation to HD. This stability can occur within or between sessions. "Within-session stability" refers to the ability of a cell to maintain a consistent preferred firing direction throughout a single recording session. "Between-sessions stability" refers to the ability of a cell to reliably represent the same preferred firing direction relative to the environment. A cell becomes unstable when the preferred firing direction of a cell changes over time, which can be classified in one of two different ways: "drift" or "shift." Drift occurs when the preferred firing direction of a cell gradually and continuously changes within a session. A shift occurs when the preferred firing direction switches rapidly to a new direction within a session or between sessions. The key difference between a drift and a shift is time: a drift occurs continuously, whereas a shift occurs abruptly. The specific conditions in which stability or instability occurred are noted in Results, along with the occurrence of drift or shift. Signal degradation and instability are not mutually exclusive, because within-session instability can lead to signal degradation. However, between-sessions instability does not lead to signal degradation.

Histology. After electrophysiological recording, mice received an overdose of sodium pentobarbital $(150 \mathrm{mg} / \mathrm{kg})$, and electrode tip locations were marked with iron deposited by anodal current (15 $\mu \mathrm{A}, 20 \mathrm{~s})$. Mice 


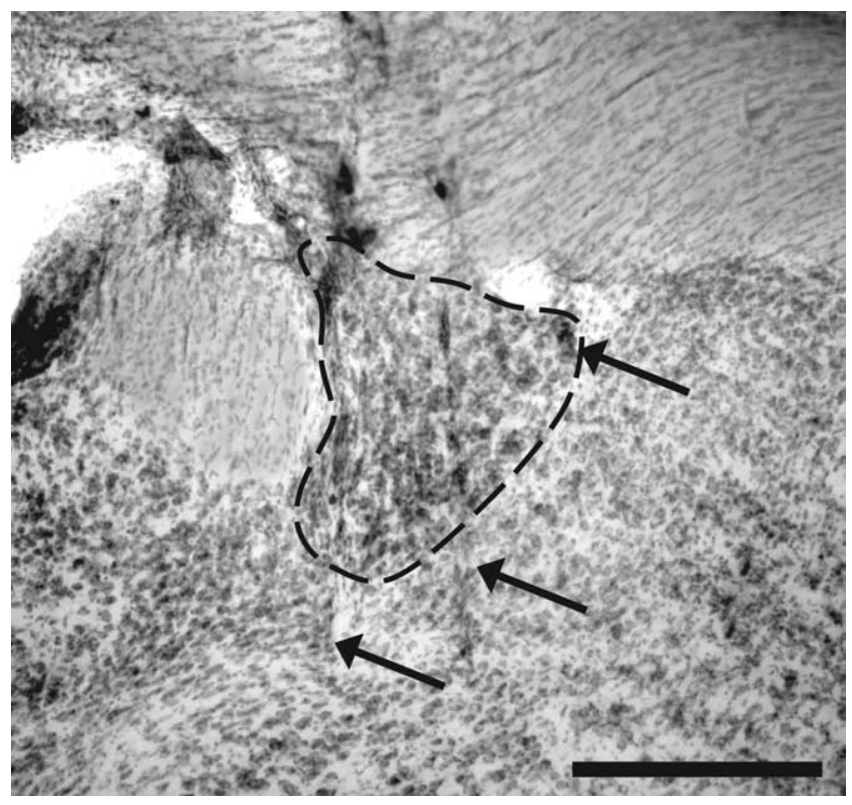

Figure 2. Coronal section of mouse brain at bregma $-0.50 \mathrm{~mm}$, stained with thionin. Dashed line indicates boundaries of ADN. Electrode penetration of ADN was verified by the presence of electrode tracks (indicated by arrows) extending through ADN. Scale bar, $300 \mu \mathrm{m}$.

were killed by transcardial perfusion with normal saline, followed by $10 \%$ Formalin. Brains were then postfixed in 10\% Formalin containing 2\% potassium ferrocyanide for $24-48 \mathrm{~h}$ to produce a Prussian blue reaction at electrode tip locations. Brains were removed from Formalin and placed in $20 \%$ sucrose for cryoprotection before being sectioned at 50 $\mu \mathrm{m}$ on a cryostat. Brain sections containing ADN were mounted on gelatin-coated microscope slides. Brain tissue was rehydrated before being stained with thionin and then dehydrated and covered with glass before examination under light microscopy. Electrode position in ADN was verified by electrode tracks through ADN and Prussian blue reaction ventral to $\mathrm{ADN}$.

\section{Results}

\section{C57BL/6J mice}

Histological analysis revealed that recording electrodes penetrated the ADN of five C57BL/6J mice (Fig. 2). In two additional mice, electrode penetration of ADN could not be verified because of tissue damage that occurred during histological procedures, although one HD cell was recorded from each of these animals. A previous report in rats has shown HD cell activity outside of ADN along the border between the anterior ventral and ventral anterior thalamic nuclei, but this HD cell activity is similar to that of the ADN (Yoganarasimha and Knierim, 2005). Data from these two animals were included in analyses, because no other anterior thalamic areas are known to contain HD cells.

In C57BL/6J mice, the waveforms of 109 cells were isolated from background noise while the electrode bundle was estimated to be located between the dorsal and ventral bounds of ADN. The total number of cells recorded from the two mice with inconclusive histology was conservatively estimated, because electrode locations between the dorsal and ventral bounds of ADN could not be verified. Of these 109 cells, 24 cells $(22.0 \%)$ were classified as HD cells, indicated by a significantly increased firing rate as a function of HD (Rayleigh's $r \geq 0.4$ ), and resembled HD cells recorded in rats. This percentage is somewhat conservative, however, because the width of the electrode bundle caused some individual electrode wires to miss the ADN, whereas other wires penetrated ADN (Table 1). The present experimental procedures prevented histological determination of which electrode tracks were produced by wires that encountered HD cells.

For five HD cells, waveform isolation deteriorated during the course of recording. Of the $24 \mathrm{HD}$ cells with well isolated waveforms during session 1, 22 cells remained well isolated through session 2, 20 cells remained well isolated through session 3, and 19 cells remained isolated through sessions 4 and 5 . The number of cells used for each session analysis reflects the group of cells with well isolated waveforms.

Multiple HD cells were simultaneously recorded on five occasions (three pairs, two triplets). In each case, the preferred firing directions of simultaneously recorded HD cells were separated by an angular distance that remained relatively constant across sessions. Figure $3 A$ illustrates three classic HD cells recorded simultaneously from the same C57BL/6J mouse. Supplemental Figure S2 (available at www.jneurosci.org as supplemental material) illustrates the tuning curves of all HD cells not depicted in the text as well as additional ADN cells that showed some directional modulation but did not reach the significance criterion to be classified as HD cells.

\section{Otoconia-deficient tilted mice \\ HD cells}

Histological analysis revealed that recording electrodes penetrated the ADN of eight tilted mice. The waveforms of 79 cells were isolated from background noise while the electrode bundle was located between the dorsal and ventral bounds of ADN. The number of cells recorded from the ADN per tilted mouse was not significantly different from control mice $\left(\chi_{(1)}^{2}=0.726 ; p>\right.$ $0.05)$. Of the $79 \mathrm{ADN}$ cells in tilted mice, nine (11.4\%) were classified as HD cells, indicated by a significantly increased firing rate as a function of HD (Rayleigh's $r \geq 0.40$ ). The directional tuning curve of a representative tilted HD cell is depicted in Figure $3 B$. All nine HD cells were recorded from four mice, and the tuning curves of HD cells not shown in the text are depicted in supplemental Figure S3 (available at www.jneurosci.org as supplemental material). In the other four mice, single-unit activity was recorded while the electrodes were within the dorsoventral bounds of ADN, but none of these cells reached the significance criterion to be classified as HD cells. Additional tuning curves of ADN cells in tilted mice that showed directional modulation, but did not reach the significance criterion to be classified as HD cells, are also illustrated in supplemental Figure S3 (available at www. jneurosci.org as supplemental material). The number of ADN cells that were significantly modulated by HD was lower in tilted mice compared with controls ( 11.4 vs $22.0 \% ; \chi_{(1)}^{2}=4.586 ; p<$ $0.05)$. HD cell frequencies for C57BL/6J and tilted mice are described in Table 1. For one cell with significant directional activity during session 1 , recording was terminated after loss of significant directional firing during session 2, although the waveform continued to be isolated from background noise. For all other HD cells in tilted mice, recording continued for five sessions and all waveforms were well isolated from background noise.

\section{Bursty cells}

In seven of the eight tilted mice, 23 cells that did not reach the Rayleigh's significance criterion for classification as HD cells were subjectively classified as "bursty" cells. These cells fired in bursts with little accommodation, and the bursts did not correspond to a single HD; thus, the average tuning curve of each cell showed a relatively uniform spike distribution (Fig. 4A). These bursts of activity were not periodic but instead appeared to occur at random intervals throughout the recording session, indepen- 
Table 1. Description of cells recorded from $\mathrm{C57BL} / 6 \mathrm{~J}$ and otoconia-deficient tilted mice while the electrode tips were located within the dorsoventral bounds of ADN

\begin{tabular}{|c|c|c|c|c|c|c|}
\hline \multirow[b]{2}{*}{ Animal ID } & \multicolumn{3}{|l|}{ (57BL/6) } & \multicolumn{3}{|l|}{ tilted } \\
\hline & Total cells & HD cells & Bursty cells & Total cells & HD cells & Bursty cells \\
\hline 1 & 10 & 1 & 0 & 16 & 2 & 1 \\
\hline 2 & 12 & 1 & 0 & 7 & 1 & 0 \\
\hline 3 & 10 & 3 & 0 & 6 & 2 & 3 \\
\hline 4 & 11 & 3 & 2 & 16 & 4 & 0 \\
\hline 5 & 6 & 1 & 0 & 13 & 0 & 2 \\
\hline 6 & 23 & 7 & 0 & 5 & 0 & 2 \\
\hline 7 & 37 & 8 & 1 & 10 & 0 & 4 \\
\hline 8 & & & & 6 & 0 & 1 \\
\hline Sum & 109 & 24 & 3 & 79 & 9 & 13 \\
\hline Average/animal & 15.57 & 3.43 & 0.43 & 9.88 & 1.13 & 1.63 \\
\hline
\end{tabular}

Bursty cells were seen most frequently in tilted mice and fired in aperiodic bursts as the mice moved about the arena. The activity of some bursty cells subjectively appeared to be directionally modulated but did not reach significance. brief CCW head turns. This burst activity is best exemplified by the firing rate versus time plots in Figure 4C. Compare the activity pattern of the bursty cell (top graph) with the similar type of burst activity for an HD cell (middle graph) and the different pattern seen for a non-HD, non-bursty cell (bottom graph). In particular, note that the bursty cell becomes virtually silent between the prominent bursts of activity. This lack of activity between bursts is distinct from the moderate baseline firing rate of most nondirectional C57BL/6J cells, which showed considerable rate variability but did not cease firing between periods of high firing rates.

Several analyses were conducted to de-
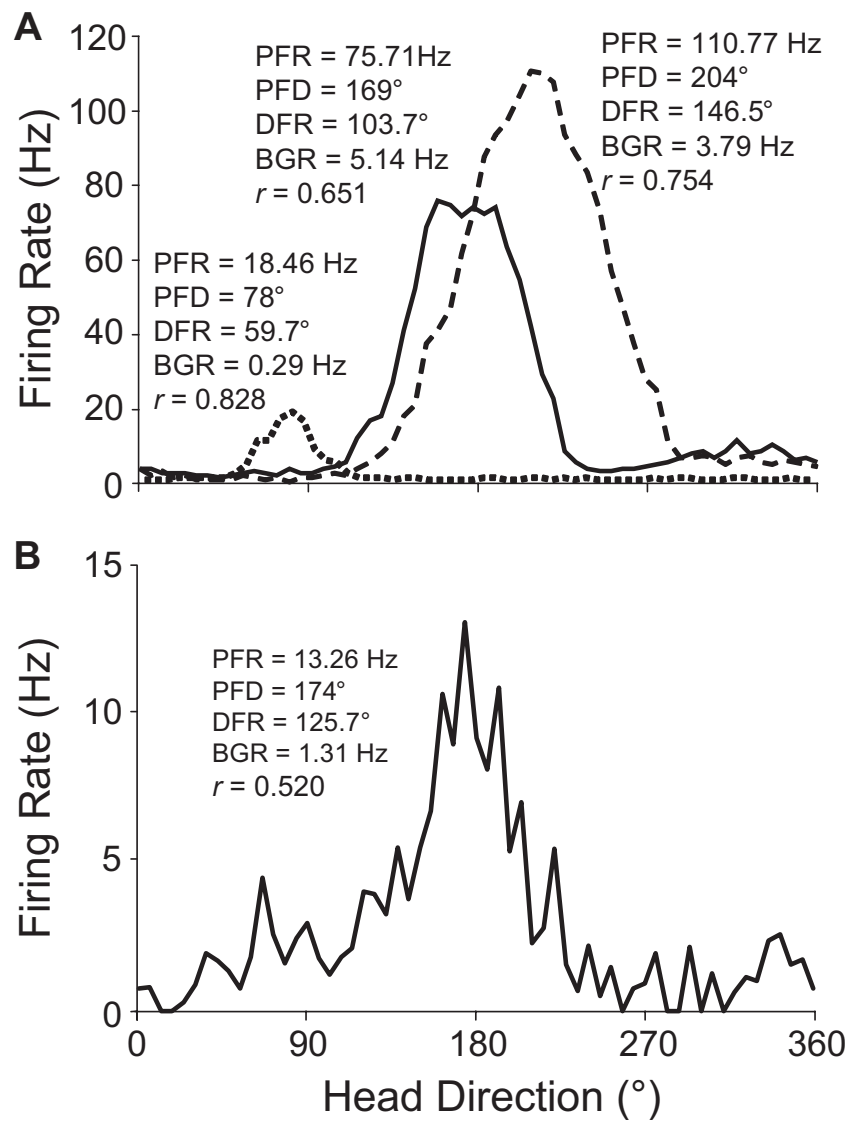

Figure 3. Directional tuning curves of $\mathrm{HD}$ cells in $(57 \mathrm{BL} / 6 \mathrm{~J}$ and tilted mice. $A$, Robust directional tuning of three classic $\mathrm{HD}$ cells recorded simultaneously on different electrodes from the same C57BL/6J mouse. Peak firing rate (PFR), preferred direction (PFD), directional firing range (DFR), and background firing rate (BGR) are unique to each HD cell. $B$, Tuning curve of a representative $H D$ cell recorded from a tilted mouse. Note the variable background firing rate (outside of the directional firing range) for the tilted $\mathrm{HD}$ cell, which contrasts with the relatively uniform background firing rates of (57BL/6) HD cells. Rayleigh's $r$ value is noted for each cell.

dent of the animal's HD. The pattern of burst activity observed in these nondirectional cells differs from that of unstable C57BL/6J cells in darkness (described below and depicted in Fig. 9D), which showed a unidirectional preferred firing direction drift throughout the recording session. The cell depicted in Figure 4 was recorded as the mouse navigated primarily in a CW direction throughout the recording session, resulting in bursts of activity that also shifted primarily in a CW direction (Fig. $4 B$ ). For this cell, bursts occurred during long $\mathrm{CW}$ head turns as well as during termine whether bursty cells show unique firing characteristics relative to HD and non-directional ADN cells. First, a burst analysis was conducted to determine whether the spike trains of the cells in question included discrete bursts of activity similar to those of HD cells. HD cell spike trains consist of long periods of inactivity, punctuated by bursts of activity with variable frequency and duration that depend on the animal's behavior. To compare spike train features between cell types, we calculated a burst index for each HD and nondirectional cell (see Materials and Methods). For HD cells, the mean burst index was $0.620 \pm$ 0.0327 (range, $0.375-0.915$ ). For nondirectional cells, the mean burst index was $0.017 \pm 0.030$ (range, $0.000-0.410$ ). To provide a conservative estimate of the number of bursty cells recorded from tilted mice, we adopted a burst index criterion of 0.400 . For the 23 tilted cells that were subjectively categorized as bursty, the mean burst index was $0.450 \pm 0.042$ (range, 0.077-0.752). We eliminated one cell from this analysis because of an abnormally low mean firing rate that resulted in a burst index of 1.000. Of the 22 remaining cells, 13 cells had burst index values greater $>0.40$. These 13 cells were therefore quantitatively categorized as having bursty spike patterns similar to those of HD cells. Importantly, only 3 nondirectional cells in two of seven C57BL/6J mice versus 13 nondirectional cells in six of eight tilted mice met the quantitative criterion to be classified as bursty. The probability of recording a bursty cell was significantly greater in tilted mice than in C57BL/6J mice $\left(\chi_{(1)}^{2}=11.046, p<0.001\right)$.

To further determine the spiking characteristics of bursty cells, interspike interval histograms were constructed to determine whether the firing patterns of quantitatively categorized bursty cells were more similar to HD cells or to nondirectional cells. However, no distinguishing characteristics of bursty cells were found compared with other nondirectional cells or to HD cells (supplemental Fig. S4, available at www.jneurosci.org as supplemental material). To determine whether tilted mice locomoted more or less during sessions in which bursty cells were recorded relative to sessions in which HD cells were recorded, we calculated the overall distance the rat traversed during the $8 \mathrm{~min}$ recording session. Each session was counted only once, whether single or multiple bursty cells were recorded during the session. For the 11 sessions during which the 13 bursty cells were recorded, the mean overall distance traveled was $1037.94 \pm 106.64$ $\mathrm{cm}$ (range, 651.93-1853.69 cm). During sessions in which HD cells were recorded from tilted mice, the mean total distance traveled was $1333.90 \pm 211.06 \mathrm{~cm}$ (range, $789.86-2532.00 \mathrm{~cm}$ ). The total distance traveled by tilted mice was not significantly greater during sessions in which HD cells were recorded relative to those 

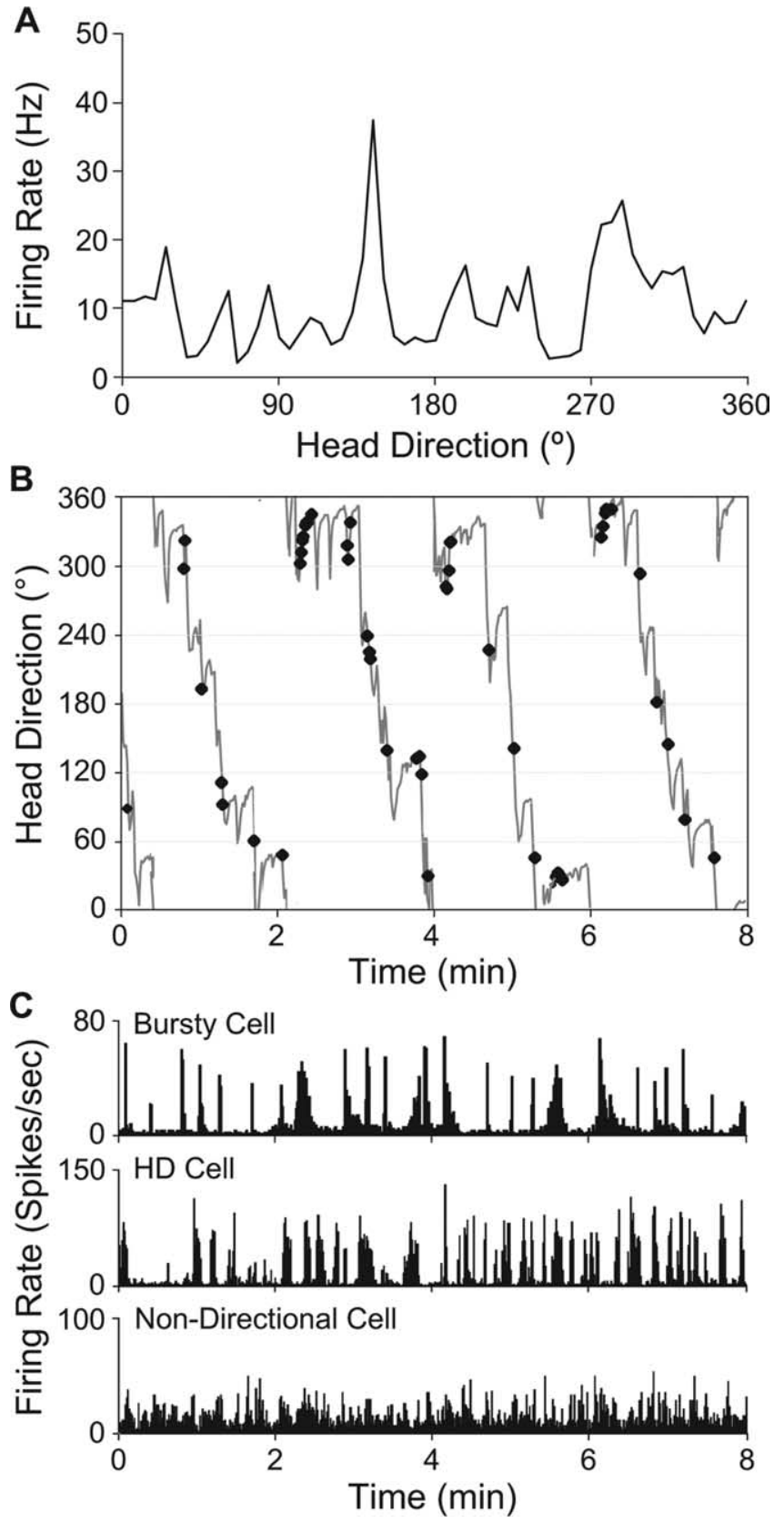

Figure 4. A, Directional tuning curve recorded from a bursty ADN cell recorded from a tilted mouse. $\boldsymbol{B}$, Firing rate $\times H D \times$ time plot showing the activity peaks of the bursty cell depicted in $A$. Qualitatively, this ADN cell showed firing characteristics similar to those of HD cells in C57BL/6J mice but lacked a consistent preferred firing direction. As the mouse navigated around the arena in a CW direction, the cell fired in bursts, with most bursts followed by a period of inactivity. Solid line indicates actual HD throughout the recording session, and points indicate $\mathrm{HD}$ and time at which the firing rate reached $75 \%$ of the maximum firing rate of the cell. C, Firing rate plots depicting cellular activity throughout the 8 min recording session. Top, The bursty cell shown in $\boldsymbol{A}$ and $\boldsymbol{B}$ (burst index, 0.66). Middle, A typical C57BL/6J HD cell (burst index, 0.74). Bottom, A typical C57BL/6J nondirectional ADN cell (burst index, 0.18). Note the presence of distinct bursts, followed by relative inactivity, for the bursty cell and the HD cell, which contrasts with the uniform firing rate of the nondirectional cell. Temporal resolution, $1 \mathrm{bin}=1 \mathrm{~s}$.

sessions in which bursty cells were recorded $\left(t_{(16)}=1.39 ; p=\right.$ $0.185)$.

If bursty cells in tilted mice are indeed similar to HD cells, which appear to be part of an attractor network, the bursts of activity of one cell would remain in register with those of other bursty cells. This prediction also suggests that, during head turns, the order of bursts would depend on the direction of head turn. In the present study, two bursty cells were simultaneously recorded from one tilted mouse on two occasions. For each head turn during these sessions, we determined the burst order, as indicated by the onset time for each burst, along with the associated turn direction. For one pair of cells, the animal made eight CW turns and five CCW turns. In every CW turn, the bursts of cell 2 preceded the bursts of cell 1 , and, in every CCW turn, the bursts occurred in the reverse order. For the second pair of cells, the animal made four CW turns and five CCW turns. For every CW turn, cell 2 preceded cell 1 , and, for every CCW turn, cell 1 preceded cell 2 (Fig. 5). Thus, the fact that these bursty cells remain in register is consistent with the hypothesis that these bursty cells are similar to HD cells in C57BL/6J mice. Furthermore, the consistent order of burst activity found in these cells is similar to that of nondirectional bursty ADN cells in chinchillas after bilateral occlusion of their semicircular canals (Muir et al., 2004; Brown et al., 2006).

Assuming that HD cell activity is based on a ring attractor network, rhythmic burst activity could arise if a network becomes disconnected from its external inputs, and the activity hill drifts around the ring network at a fixed rate. In this scenario, one would expect to observe activity bursts at fixed intervals when recording from a single cell that is part of the disconnected network. The firing rate versus time plot for the bursty cell in Figure $4 B$ appears somewhat rhythmic and would provide support for this view. However, the bursts appear rhythmic because of the timescale used in the graph. When the time intervals between burst onsets are analyzed for this cell, they generally did not occur at fixed intervals and varied more than is apparent from the plot in Figure $4 B$. The interburst interval of this cell is shown labeled in red on supplemental Figure S5 (available at www.jneurosci.org as supplemental material), which plots the time intervals between burst onsets for the 13 cells classified as bursty. Other bursty cells also did not generate bursts at a particular rhythm. The nonflat curves for each cell indicates that activity bursts did not occur at regular intervals. However, because the semicircular canals, along with proprioceptive and motor efference signals, are still intact in tilted mice, it is possible that, if the nature of their movements is taken into account, especially the directions they are turning their heads, the onset of bursts might be more predictable.

Bursty cells were found in two of the four tilted mice in which HD cells were identified on different days. In fact, one of the bursty cells in a tilted mouse had been recorded on the previous day and showed significant directional activity on the first day of recording. These findings, along with the fact that $\mathrm{HD}$ cells and bursty cells were not recorded simultaneously, suggest that the HD system of tilted mice may maintain a stable HD representation during some trials but fails to maintain this stable HD representation across trials. Thus, these bursty ADN cells could be HD cells that failed to maintain directionality across trials, and this failure appears to have resulted from the absence of an otolithic signal. This failure to maintain directionality could be interpreted as perceptual disorientation. However, there was a trend for tilted mice to locomote less during trials in which bursty cells were recorded relative to trials in which HD cells were recorded, and this result is not consistent with previous studies suggesting increased movement after vestibular inactivation (Ossenkopp et al., 1990). Alternatively, it is possible that two types of HD cells exist: one that relies heavily on otolithic input and another that relies predominantly on non-otolithic inputs, although this explanation would have difficulty accounting for the 

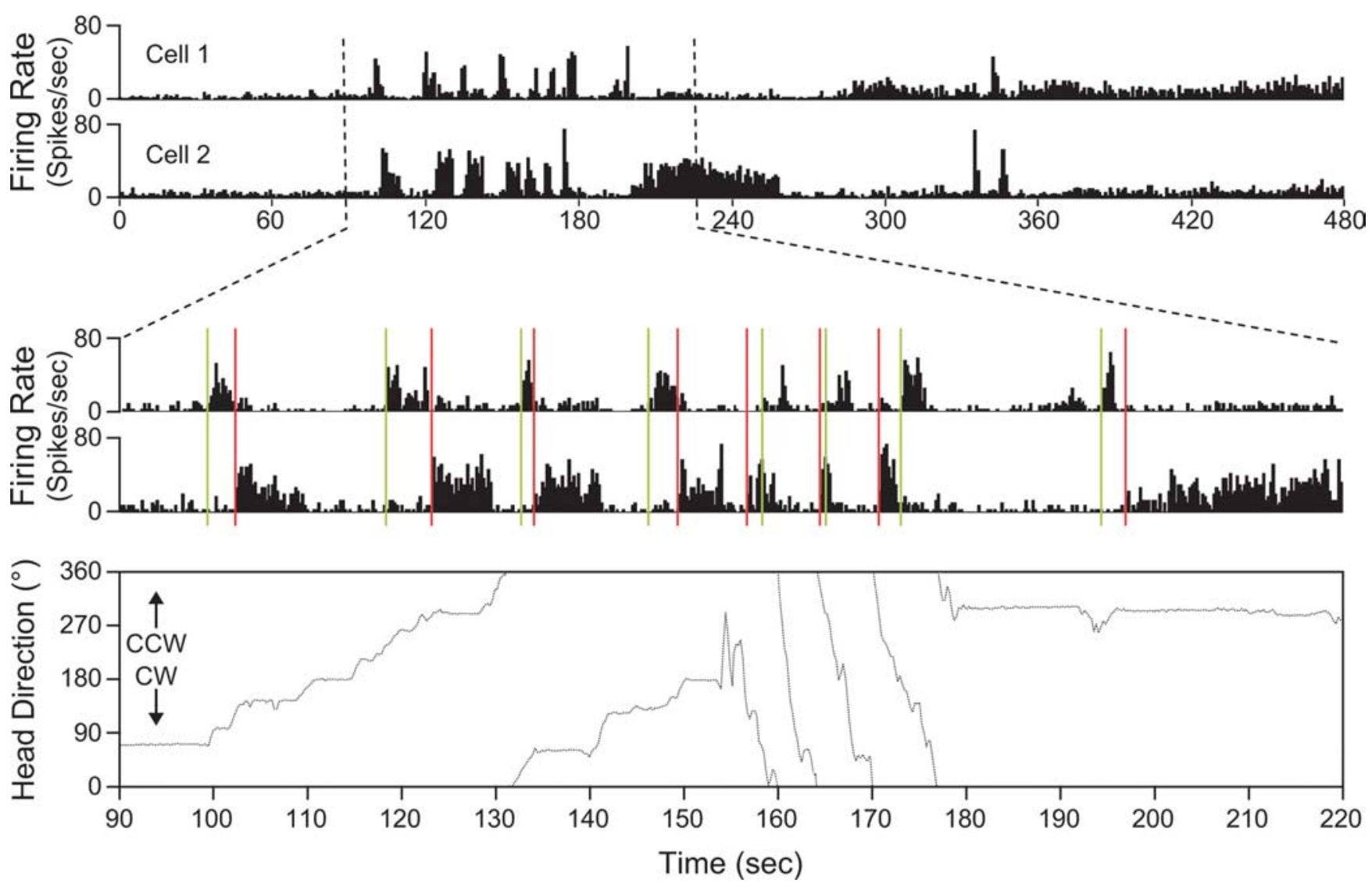

Figure 5. Activity of simultaneously recorded bursty cells in a tilted mouse during head turns. Timescale for firing rate plots in inset corresponds to head direction plot (bottom). At the beginning of the recording session, the animal remained relatively motionless for $\sim 100 \mathrm{~s}$, after which the animal began to move about the arena. During CCW head turns, activity burst onset for cell 1 (indicated by vertical green line) preceded activity burst onset for cell 2 (indicated by vertical red line). After a transition to CW head turns at $t=155 \mathrm{~s}$, activity burst onset for cell 2 preceded activity burst onset for cell 1 . After another transition at $t=193 \mathrm{~s}$, burst onset for cell 1 again preceded burst onset for cell 2 . After this period of behavioral activity, the animal remained relatively motionless for the remainder of the recording session, with the exception of a continuous C CW head turn between $t=333$ and $t=352 \mathrm{~s}$. Temporal resolution, 1 bin $=1 \mathrm{~s}$; inset, 1 bin $=250 \mathrm{~ms}$.

Table 2. HD cell firing properties in mice and rats

\begin{tabular}{|c|c|c|c|c|c|c|}
\hline \multirow[b]{2}{*}{ Parameter } & \multicolumn{2}{|c|}{ C57BL/6J HD cells $(n=24)$} & \multicolumn{2}{|c|}{ Tilted HD cells $(n=9)$} & \multicolumn{2}{|c|}{ Rat HD cells $(n=37)$} \\
\hline & Mean \pm SEM & Range & Mean \pm SEM & Range & Mean \pm SEM & Range \\
\hline Background firing rate (spikes/s) & $1.83 \pm 0.28$ & $0.017-5.14$ & $2.89 \pm 0.92$ & $0.63-8.07$ & $1.99 \pm 0.35$ & $0.04-13.24$ \\
\hline Signal-to-noise ratio & $68.58 \pm 43.07$ & $5.66-1056.71$ & $23.19 \pm 8.12$ & $7.86-78.00$ & $76.05 \pm 38.69$ & $5.11-1422.5$ \\
\hline Peak firing rate (spikes/s) & $35.17 \pm 4.72$ & $4.29-110.77$ & $37.24 \pm 6.80$ & $11.13-64.40$ & $41.08 \pm 4.40$ & $7.79-118.06$ \\
\hline Directional firing range $\left(^{\circ}\right)$ & $141.58 \pm 8.83^{* *}$ & $59.72-230.03$ & $124.25 \pm 9.23$ & $88.85-163.41$ & $96.24 \pm 3.25$ & $60.94-142.97$ \\
\hline SD of directional firing range $\left({ }^{\circ}\right)$ & $39.62 \pm 4.23^{* *}$ & $18.21-91.86$ & $35.29 \pm 5.92$ & $10.61-61.97$ & $25.08 \pm 2.61^{\dagger}$ & $9.59-73.17^{\dagger}$ \\
\hline Directional information content (bits) & $0.918 \pm 0.103^{* *}$ & $0.31-2.25$ & $0.519 \pm 0.095$ & $0.24-0.94$ & $1.27 \pm 0.097^{\dagger}$ & $0.34-2.45^{\dagger}$ \\
\hline Gaussian fit $(r)$ & $0.941 \pm 0.011$ & $0.810-0.995$ & $0.846 \pm 0.040^{*}$ & $0.615-0.942$ & $0.94 \pm 0.014^{\dagger}$ & $0.544-0.997^{\dagger}$ \\
\hline Anticipatory time interval (ms) & $39.76 \pm 6.63^{* *}$ & -12.55 to 110.25 & $30.48 \pm 13.27$ & -16.14 to 92.95 & $18.97 \pm 3.67^{\dagger}$ & -14.77 to $79.43^{\dagger}$ \\
\hline Rayleigh's rvalue & $0.686 \pm 0.024$ & $0.419-0.922$ & $0.528 \pm 0.020^{*}$ & $0.465-0.614$ & $0.706 \pm 0.026^{\dagger}$ & $0.423-0.955^{\dagger}$ \\
\hline
\end{tabular}

Summary of $\mathrm{C} 57 \mathrm{BL} / 6 \mathrm{~J}$ and tilted mouse $\mathrm{HD}$ cell firing properties are presented for comparison with firing characteristics of rat $\mathrm{HD}$ cells. ${ }^{\dagger} \mathrm{HD}$ cells from rats (Taube, 1995$)$ were reanalyzed to provide previously unreported firing properties. *Tilted mouse values that are significantly different from $\left(57 \mathrm{BL} / 6 \mathrm{~J}\right.$ mice. ${ }^{* *}(57 \mathrm{BL} / 6 \mathrm{~J}$ values that are significantly different from rats.

finding that HD and bursty cells were never encountered together during a single recording session. Another possible explanation for the presence of bursty cells in tilted mice is that these cells are similar to C57BL/6J cells, which appeared to be directionally modulated but did not reach the Rayleigh's significance criterion to be classified as HD cells (range, 0.177-0.383). However, the spike trains of only two of these C57BL/6 J cells showed discrete bursts of activity, and bursty cells in tilted mice were, in this way, dissimilar to most nondirectional cells of C57BL/6J mice. Table 1 summarizes the percentage of HD and bursty cells found in C57BL/6J and tilted mice.
Firing characteristics of $\mathrm{HD}$ cells in $\mathrm{C} 57 \mathrm{BL} / 6 \mathrm{~J}$ mice compared to $\mathrm{HD}$ cells in rats

For summary and comparison, Table 2 shows the firing characteristics of HD cells from C57BL/6J and tilted mice identified in the present study, as well as rat ADN HD cells reported in a previous study (Taube, 1995). Firing characteristics presented from all mice were acquired during the first standard session (session 1) unless otherwise noted.

In general, C57BL/6J mice HD cell properties were similar to those of rats for background firing rate, peak firing rate, signalto-noise ratio, Gaussian fit, and Rayleigh's $r$ (Table 2). In con- 
trast, there was a significant difference for several properties between the two species, including directional firing range (mice had, on average, $47 \%$ broader tuning curves), information content (mice had, on average, $28 \%$ lower values), and ATI (mice displayed, on average, approximately twice the amount of anticipation). During recordings of C57BL/6J HD cells, we noticed that the preferred firing direction often appeared to be less stable than that previously observed in rats. Consequently, this instability could lead to a wider directional firing range and a less robust tuning curve, which in turn would result in a smaller information content value in mice.

To determine whether the preferred firing directions were indeed less stable in mice compared with rats, the firing rate $\times$ $\mathrm{HD} \times$ time analysis was used to analyze the HDs at which the cell fired $\geq 75 \%$ of its maximum within-session peak firing rate. For this analysis, cell firing and HDs were summed and then averaged over 60 1/60 s bins ( $1 \mathrm{~s})$. A cell that is stable should fire within a narrow range of HDs, whereas a cell that is unstable should fire over a larger range of HDs. The SD of this range of HDs was used as an index of the variability for the preferred firing direction of the cell. The mean of the SD values obtained from C57BL/6J HD cells was then compared with the mean of SD values obtained from a reanalysis of previously reported rat ADN HD cells (Taube, 1995). C57BL/6J HD cells had SD values of mean $39.62 \pm$ $4.23^{\circ}$ (range, $18.21-91.86^{\circ}$ ). Rat HD cells showed SD values of mean $25.08 \pm 2.61^{\circ}$ (range, $\left.9.59-73.17^{\circ}\right)$. A $t$ test comparison indicates that $\mathrm{C} 57 \mathrm{BL} / 6 \mathrm{~J} \mathrm{HD}$ cells had greater variability in the HDs at which the cell fired at $75 \%$ of its peak firing rate than rat HD cells $\left(t_{(59)}=3.095 ; p=0.003\right)$. One possible cause of increased variability during a recording session is the greater ATI of mouse HD cells. However, ATI values were not significantly correlated with directional firing range $(r=0.184 ; p=0.39)$. Thus, the increased variability may be associated with a less accurate perception of HD over time, although additional study is required to conclusively determine the perceptual or behavioral significance of differences between the directional firing ranges of $\mathrm{HD}$ cells in rats and mice. In summary, we attribute the broader tuning curves and lower information content values in C57BL/6J mice to the reduced precision of their preferred firing directions within a recording session.

Finally, it is important to note that, although C57BL/6J HD cells had wider directional firing ranges, they did not have lower peak firing rates, as would be predicted by the increased variability in spreading out the maximal firing of the cell over a larger number of directional bins over the course of a recording session. This finding may imply that C57BL/6J HD cells may, in fact, have larger peak firing rates than rat HD cells, and the increased peak firing rate is masked by the increased variability in the preferred firing direction.

As mentioned above, ATI values were greater (more positive, corresponding to earlier anticipation) in C57BL/6J mice than in rats $\left(t_{(58)}=2.959 ; p=0.005\right)$. Although it is possible that this difference may be attributed to the drift in the preferred directions of the cells, Bassett et al. (2005) demonstrated that increasing the variability of the preferred direction and the directional firing range by adding noise to HD measurements did not change the ATI values dramatically and, in most cases, actually decreased it. This finding therefore suggests that the increased ATI values in C57BL/6J ADN HD cells cannot be attributed to their broader directional firing range. It is important to note, however, that adding noise to increase tuning curve width to simulate variability in the preferred firing direction also reduces the peak firing rate of the tuning curve, a finding that did not co-occur with the increased directional range. Therefore, we cannot completely rule out the possibility that instability of the preferred firing direction led to the higher ATI values.

\section{Firing characteristics of HD cells in C57BL/6J mice compared to tilted mice}

\section{Background firing rate}

The background firing rate for HD cells recorded from C57BL/6 mice was low (mean, $1.83 \pm 0.28$ spikes/s). In tilted mice, the mean background firing rate was $2.89 \pm 0.92$ spikes/s. Background firing rates did not differ between $\mathrm{C} 57 \mathrm{BL} / 6 \mathrm{~J}$ and tilted mice $\left(t_{(31)}=1.49 ; p=0.147\right)$.

\section{Peak firing rate}

The mean peak firing rates for C57BL/6J and tilted HD cells were $35.17 \pm 4.72 \mathrm{spikes} / \mathrm{s}$ (range, $4.29-110.77 \mathrm{spikes} / \mathrm{s}$ ) and $37.24 \pm$ $6.80 \mathrm{spikes/s}$ (range, 11.13-64.40 spikes/s), respectively. Peak firing rates of $\mathrm{HD}$ cells of tilted mice did not differ from those of C57BL/6J mice $(p>0.05)$. Peak firing rates were correlated with background firing rates for both groups: C57BL/6J, $r=0.732$, $p<0.0001$; tilted, $r=0.670, p<0.0001$. As in previous studies with rats, high and low peak firing rates were observed for different HD cells within the same animal for both groups. The physiological importance of peak rate variability between cells within the same animal is presently unknown. The mean $\mathrm{S} / \mathrm{N}$ ratios for HD cells in C57BL/6J and tilted mice were $68.58 \pm 43.07$ and $23.19 \pm 8.12$, respectively. Although the $\mathrm{S} / \mathrm{N}$ ratio appears much larger in $\mathrm{C} 57 \mathrm{BL} / 6 \mathrm{~J}$ than tilted mice, this difference was not statistically significant $(p>0.05)$.

\section{Directional firing range}

The mean directional firing range in C57BL/6J mice was $141.58 \pm 8.83^{\circ}$, which, as noted above, is considerably larger than the $\sim 90^{\circ}$ value observed in rats (Taube, 1995). In tilted mice, the mean directional firing range was $124.25 \pm 9.23^{\circ}$. The directional firing range of tilted mice did not differ from that of C57BL/6J mice $(p>0.05)$. Using the firing rate $\times \mathrm{HD} \times$ time analysis to calculate the SD of the HDs when the cell fired $\geq 75 \%$ of its maximum firing rate (as described above), we found no difference between C57BL/6J HD cells (mean, $39.62 \pm 4.23^{\circ}$ ) and tilted HD cells $\left(\right.$ mean, $\left.35.29 \pm 5.92^{\circ}\right)\left(t_{(31)}=0.554 ; p=0.58\right)$.

\section{Gaussian r}

With the preferred firing direction for each cell centered on the mean, a Gaussian distribution was fit to recorded data. The mean correlation between the data and best-fit Gaussian curve was $0.941 \pm 0.011$ for $\mathrm{C} 57 \mathrm{BL} / 6 \mathrm{~J}$ mice and $0.846 \pm 0.040$ for tilted mice. The Gaussian $r$ for HD curves from tilted mice was significantly lower than for HD curves from C57BL/6J mice $\left(t_{(31)}=\right.$ $3.15 ; p=0.0036)$.

\section{Directionality measures}

The mean directional information content for C57BL/6J HD cells was $0.918 \pm 0.103$ bits, whereas this measure was $0.519 \pm 0.095$ bits for tilted mice. Although the information content score was much lower for tilted mice than C57BL/6J mice, this comparison did not quite reach significance $\left(t_{(29)}=1.999 ; p=0.055\right)$. An accurate information content score could not be calculated for two HD cells recorded from a tilted mouse because both cells were recorded simultaneously on the same electrode.

Another method for measuring the extent of directional information represented by HD cell activity is to analyze the Rayleigh's $r$ values calculated from tuning curves. Across HD cells that met the directional criterion of Rayleigh's $r>0.4$, the mean 


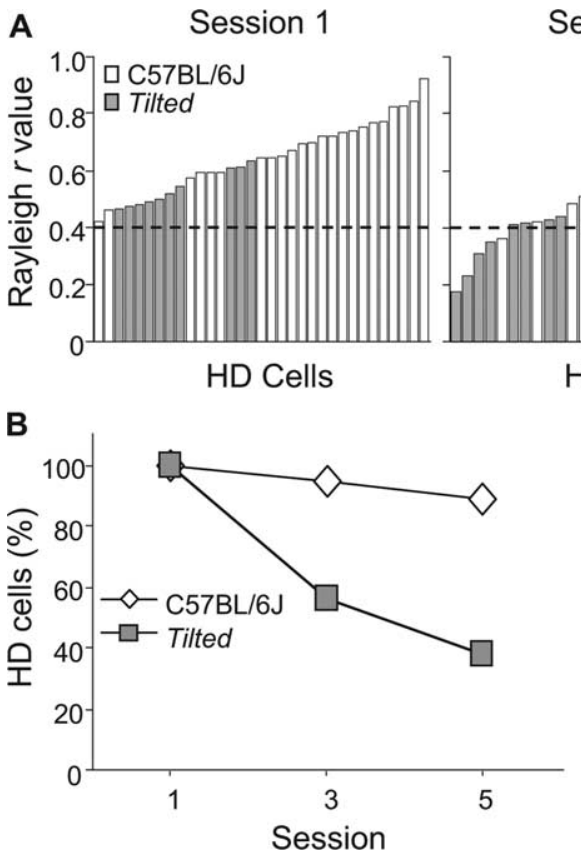

Session 3

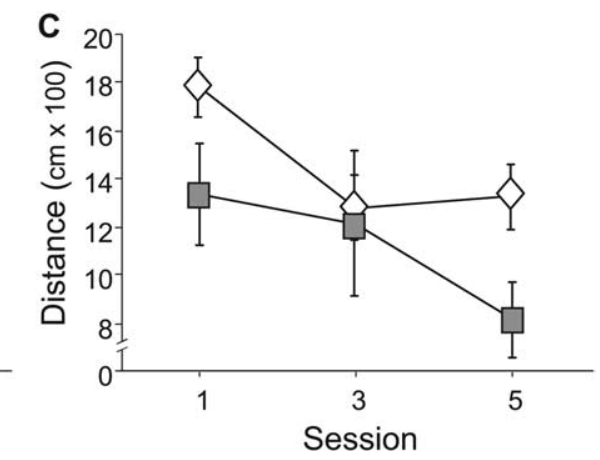

Figure 6. HD signal of tilted HD cells degraded across recording sessions. $\boldsymbol{A}$, Histogram of Rayleigh's $r$ values across standard recording sessions. Most cells from tilted mice had lower $r$ values than $(57 \mathrm{BL} / 6 \mathrm{~J}$ and are clustered to the left in each plot. In C57BL/6J mice, the activity of most HD cells maintained significant directional tuning across recording sessions. In contrast, most tilted cells that showed a significant preferred firing direction in session 1 showed reduced directional tuning across sessions. By the third recording session, nearly one-half of the HD cells became nondirectional. By the fifth recording session, most HD cells in tilted mice became nondirectional, with Rayleigh's $r$ values that fell below the directional significance criterion (dashed line). $\boldsymbol{B}$ Percentage of HD cells that remained significantly directional across standard recording sessions. In session 1, all HD cells were significantly directional. Across subsequent recording sessions, most C57BL/6J HD cells remained significantly directional, whereas most tilted $\mathrm{HD}$ cells became nondirectional. $\mathrm{C}$, Total distance (centimeters) traveled during standard recording sessions for $(57 \mathrm{BL} / 6 \mathrm{~J}$ and tilted mice.

$r$ values for C57BL/6J and tilted mice were $0.686 \pm 0.024$ and $0.528 \pm 0.020$, respectively. Figure $6 \mathrm{~A}$ (left) plots the distribution of $r$ values across both groups of mice and shows that there was a strong trend for tilted mice to have smaller $r$ values. Together, the Rayleigh $r$ and directional information content analyses suggest that the directional tuning of tilted $\mathrm{HD}$ cells is lower than that of C57BL/6J mice.

\section{Anticipatory time interval}

As previously reported in the rat ADN, HD cell activity in the mouse ADN usually predicts impending HD during head turns by showing the highest firing rate several milliseconds before the head actually faces the preferred direction of the cell (Fig. 7A) (Blair and Sharp, 1995; Blair et al., 1997; Taube and Muller, 1998). Because of insufficient sampling in both directions that potentially biased the ATI value, one HD cell from a tilted mouse was excluded from the analysis. ATI values for all other HD cells are presented here and in Figure $7 B$. For C57BL/6J mice, the mean ATI was $39.76 \pm 6.63 \mathrm{~ms}$ (range, -12.55 to $110.25 \mathrm{~ms}$ ). In two HD cells, the ATI was negative, indicating that the preferred direction of the cells during head turns lagged behind the average preferred direction of the cells. For one pair of simultaneously recorded cells in tilted mice, session 3 was used for the ATI analysis because within-session stability was greater in session 3 than in session 1. Across tilted HD cells, the mean ATI was $30.48 \pm$ $13.27 \mathrm{~ms}$ (range, -16.14 to $92.95 \mathrm{~ms}$ ), with two HD cells showing negative ATI values. The mean ATI did not differ between C57BL/6J and tilted mice $\left(t_{(30)}=0.674 ; p=0.506\right)$, indicating that the ATI does not depend on otolith signals.
Cue control of preferred firing direction In order to determine the influence of visual landmarks on HD cell activity, the animal was placed in an opaque container, and the visual cue card was rotated $90^{\circ} \mathrm{CW}$ or CCW before the beginning of session 2 . With the visual cue rotated $90^{\circ}$, a $90^{\circ}$ shift of the preferred firing direction of an HD cell indicates strong visual control of the $\mathrm{HD}$ signal. In C57BL/6J mice, the preferred firing direction of $14 \mathrm{HD}$ cells (recorded in 10 sessions) under rotated, three HD cells (recorded in two sessions) shifted exactly $90^{\circ}$, and four HD cells (recorded in four sessions) over rotated (Fig. 8A). Overall, with the average shift of simultaneously recorded cells calculated as a single value, the average shift of preferred direction indicates an under rotation (mean, $59.73^{\circ} \pm 9.46^{\circ}$; range, -6 to $\left.108^{\circ}\right)$. This under rotation indicates that an uncontrolled environmental feature may have enabled mice to recognize that the cue card was rotated, although an effort was made to eliminate extraneous olfactory, visual, and auditory cues. However, the overall mean shift of preferred firing direction does not accurately describe the data from C57BL/6J mice, because the circular histogram in Figure $8 A$ shows a bimodal distribution in shifts of the preferred directions. One group of seven cells (recorded in five sessions) shifted slightly or not at all as a result of visual cue rotation (mean shift, $16.80 \pm 4.80^{\circ}$; range, -6 to $\left.30^{\circ}\right)$. The other group of 14 cells (recorded in nine sessions) shifted nearly $90^{\circ}$ (mean shift, $82.43 \pm 5.26^{\circ}$; range, $60-108^{\circ}$ ). Both good and poor cue control responses were observed in the same animal across different sessions. Thus, the preferred firing direction of some HD cells shifted nearly $90^{\circ}$ on one day, whereas other cells in the same animal shifted their preferred direction only slightly on a different day. In all cases when multiple cells were simultaneously recorded, however, the preferred direction of all cells shifted in register. Despite the greater or lesser shift of preferred direction across cells, rotation of the cue card influenced most HD cells, as indicated by the preferred direction of most HD cells shifting in the same direction as the visual cue.

In tilted mice, eight HD cells (recorded in six sessions) showed a stable preferred firing direction during session 2 , in which the visual cue card was rotated $90^{\circ} \mathrm{CW}$ or CCW relative to session 1 . Overall, the preferred direction of four HD cells (recorded in four sessions) shifted $<90^{\circ}$, the preferred direction of one HD cell shifted exactly $90^{\circ}$, and the preferred directions of three HD cells (recorded in three sessions) shifted $>90^{\circ}$. With the average preferred direction shift of simultaneously recorded cells calculated as a single value, the mean shift was $85.50 \pm 14.77^{\circ}$ (range, $30-$ $144^{\circ}$ ). The circular histogram for tilted mice (Fig. $6 \mathrm{~A}$, bottom) indicates that the preferred firing directions for HD cells in these animals showed relatively good cue control.

There were two occasions when two HD cells were recorded simultaneously in tilted mice. The preferred directions of cells in the first pair shifted 96 and $66^{\circ}$ after cue card rotation; in the second pair of cells, the preferred directions shifted 102 and $66^{\circ}$ in 

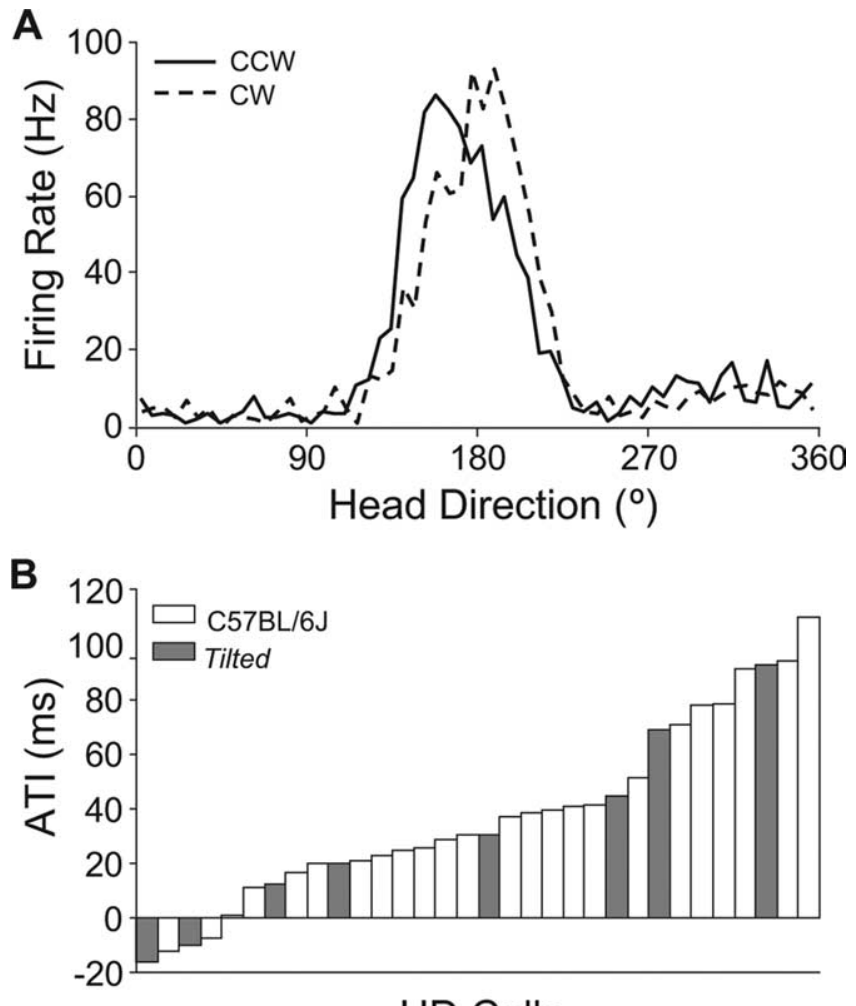

HD Cells

Figure 7. ATI of HD cells in $C 57 \mathrm{BL} / 6 \mathrm{~J}$ and tilted mice. $\boldsymbol{A}$, Firing rate as a function of head direction during $\mathrm{CCW}$ and $\mathrm{CW}$ head turns for a $\mathrm{C57BL} / 6 \mathrm{~J}$ HD cell. Preferred firing directions during CCW (solid line) and CW (dashed line) turns were shifted CW and CCW, respectively. For this session, anticipatory time interval was $36.9 \mathrm{~ms}$. $\boldsymbol{B}$, Histogram of ATI values for all HD cells recorded from $557 \mathrm{BL} / 6 \mathrm{~J}$ mice $(n=24)$ and tilted mice $(n=8)$ that met criteria for inclusion in ATI analyses. For (57BL/6J mice (open bars), plot indicates continuous range of ATI with no distinct clustering at any ATl; all except two cells show a positive ATI, indicating cell activity best predicted where the rat's head direction would be in the future. Lack of otoconia did not appear to affect the ATI, because most HD cells in tilted mice (filled bars) showed ATI values within the range of $\mathrm{C} 57 \mathrm{BL} / 6 \mathrm{~J}$ ATI values.

the card rotation session. The differences in the amount of shift between each pair of cells is larger than that usually seen in previous studies in rats, in which values are typically between 0 and $12^{\circ}$ for cell pairs (Taube et al., 1990b). The apparent mild decoupling seen between cell pairs may be attributed to the less robust tuning curves for these cells, because the Rayleigh's $r$ values for these cells was generally low for all sessions: all were below 0.7 , except for one cell for one session in which $r=0.746$. Using the cross-correlation analysis between tuning curves to determine the amount a cell shifted its preferred direction between sessions is less accurate when the tuning curves are not robust. Thus, the apparent decoupling of HD cells in otolith-deficient mice with transposed visual landmarks may be an artifact of the less robust tuning curves for these cells.

\section{HD cell stability}

HD cell stability, or the ability of an HD cell to fire reliably in response to a specific HD relative to environmental cues, was quantified using two different measures for sessions within the same day and across days. First, the stability of the HD cell was calculated as the amount of shift of the preferred firing direction between standard sessions recorded on the same day (sessions 1, 3 , and 5). When possible, we also examined the stability of the preferred direction across days. Second, HD signal degradation, or loss of direction-specific firing, was determined using the Rayleigh's $r$ value for the tuning curve of each cell across sessions.

\section{Stability within the same day}

The preferred firing direction of some C57BL/6J HD cells remained quite stable across standard sessions, whereas other cells showed considerable variability. Stability within the same day was assessed by determining the amount of directional shift in the firing rate versus HD function required to obtain the greatest correlation between sessions 1 and 3 (Fig. $8 B$ ) and between sessions 1 and 5 (Fig. $8 C$ ). As with the cue rotation analysis, we used the mean preferred firing direction shift of all simultaneously recorded cells for statistical calculations. For C57BL/6J HD cells, the preferred direction showed some variability across standard sessions 1 and 3 , with the mean shift of $1.31 \pm 7.80^{\circ}$ (range, -57 to $60^{\circ}$ ), and the mean shift between sessions 1 and 5 of $-13.50 \pm$ $7.79^{\circ}$ (range, -63 to $24^{\circ}$ ). A paired comparison test reveals that the shift of preferred direction between sessions 1 and 3 was similar to the shift between sessions 1 and $5\left(t_{(10)}=1.303 ; p=\right.$ 0.222).

For tilted HD cells that remained significantly directional through session 3, the preferred direction showed some variability between standard sessions 1 and 3 (mean, $21.00 \pm 1.73^{\circ}$; range, $\left.18-24^{\circ}\right)$ but was not significantly different compared with C57BL/6J mice $\left(t_{(15)}=1.366 ; p=0.192\right)$. For cells that remained stable through session 5 , the mean preferred direction shift between sessions 1 and 5 was $56.00 \pm 14.42^{\circ}$ (range, $36-84^{\circ}$ ), and a paired comparison test of the shifts between sessions 1 and 3 revealed no significant difference $\left(t_{(2)}=2.268 ; p=0.152\right)$. However, the shift of the preferred direction between session 1 and 5 in tilted HD cells differed from that of C57BL/6 $\mathrm{J}$ mice $\left(t_{(16)}=5.204\right.$; $p<0.0001)$. In general, the preferred firing direction of HD cells in C57BL/6J mice appeared to be fairly stable across environmentally similar conditions separated by tens of minutes, but HD cells in tilted mice became less stable over time and recording sessions.

To compare HD cell stability in mice with previously reported values from rats, we computed the absolute value of the deviation in the preferred firing direction between sessions 1 and 3 (an absolute deviation $\neq 0^{\circ}$ indicates a CW or CCW deviation from the preferred firing direction in session 1). In rat ADN HD cells, the mean absolute deviation between the first two standard recording sessions was $4.71 \pm 1.80^{\circ}$ (range, $0-18^{\circ}$ ) (Taube, 1995) (Table 3 ). In contrast, C57BL/6J mice showed a mean absolute deviation of $18.85 \pm 5.61^{\circ}$ (range, $0-60^{\circ}$ ) and was significantly greater than that of rats $\left(t_{(25)}=2.475 ; p=0.021\right)$. Thus, although the mouse HD signal remains relatively stable across recording sessions, the rat HD signal appears to be a more stable representation of actual head direction.

\section{Stability across days}

The waveforms of eight C57BL/6J HD cells were isolated from background noise across $2 \mathrm{~d}$. Although the activity of most of these cells was not recorded on both days, all HD cells subjectively appeared to remain directional across both days. The preferred direction of these HD cells remained relatively constant across both days, although a small deviation was present that was similar to the deviation observed between standard sessions recorded on the same day (described above).

\section{HD signal degradation in tilted mice}

In general, most C57BL/6J HD cells that were directional in session 1 remained directional throughout all standard sessions, whether the standard sessions occurred on the same day or across days. Exceptions include one HD cell that became nondirectional 


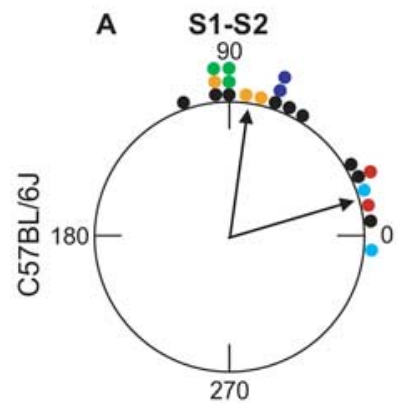

B $\quad$ S1-S3

C
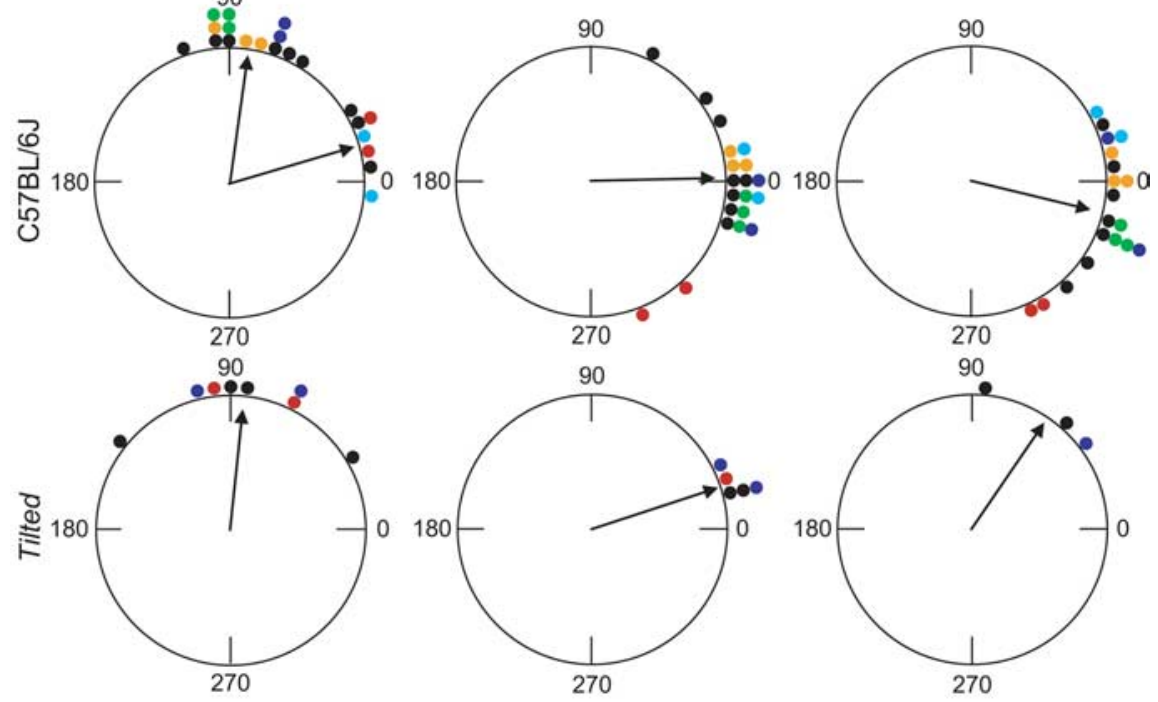

Figure 8. Shift of preferred firing direction across trials. $A$, For $C 57 \mathrm{BL} / 6 \mathrm{~J}$ mice, two clusters of preferred direction shifts occurred between sessions 1 and 2 (S1-S2) in response to $90^{\circ}$ rotation of the visual cue. One cluster consisting of $66.7 \%$ of the HD cells (recorded in 9 sessions) appears near the $90^{\circ}$ rotation (mean, $82.4^{\circ}$ ), indicating that these $\mathrm{HD}$ cells were heavily influenced by the visual cue card. The second cluster, consisting of $33.3 \%$ of the HD cells (recorded in 5 sessions), shows only a slight shift (mean, $16.8^{\circ}$ ). For tilted mice, rotation of the visual cue caused a rotation of the preferred firing direction for most HD cells (mean, $85.5^{\circ}$ ). $B, C$, The preferred firing direction of HD cells in C57BL/6 $\mathrm{J}$ mice remained fairly stable across recording sessions in which the visual cue was located in the same position relative to the room. For $\mathrm{HD}$ cells that remained significantly directional across sessions, cells from tilted mice showed greater instability than those of $\left(57 \mathrm{BL} / 6 \mathrm{~J}\right.$ mice, indicated by greater mean vector deviation from $0^{\circ}$ in the session 1-5 plot (S1-S5) relative to the session 1-3 plot (S1-S3). For presentation, the direction of preferred firing direction shift was standardized to the direction of cue rotation, in which $0^{\circ}$ represents the preferred firing direction of each $\mathrm{HD}$ cell during session 1. Black points represent individually recorded HD cells, and corresponding colors within each group represent simultaneous records from multiple HD cells. Rayleigh's vector was calculated from the mean angular shift when multiple HD cells were recorded simultaneously. Note that fewer cells are displayed across sessions for tilted mice than for $\mathrm{C} 57 \mathrm{BL} / 6 \mathrm{~J}$ mice because many cells in tilted mice lost their directional tuning after the first recording session and fell below the $r=0.4$ criterion level.

Table 3. Frequency of stable and unstable HD cells recorded from $\mathrm{C57BL} / 6 \mathrm{~J}$ mice in darkness during session 4 (S4)

\begin{tabular}{lll}
\hline ID (total S4) & Stable & Unstable \\
\hline $1(1)$ & 1 & 0 \\
$2(1)$ & 1 & 0 \\
$3(2)$ & 2 & 0 \\
$4(1)$ & 1 & 0 \\
$5(7)$ & 4 & 3 \\
$6(7)$ & 2 & 5 \\
\hline
\end{tabular}

during session 3 and two HD cells that became nondirectional during session 5 . In contrast, most HD cells from tilted mice that were directional in session 1 showed decreased directionality across subsequent recording sessions, despite the fact that the waveforms of the cells remained well isolated with no apparent change in spike amplitude. As a quantitative indicator of this decreased directionality in tilted mice, we computed the Rayleigh's $r$ values from the tuning curves of HD cells recorded during the three standard sessions (Fig. 6A). Across these sessions, the number of HD cells in C57BL/6J mice with significant directional activity for sessions 1,3 , and 5 was 24 of 24 (100\%; mean Rayleigh's $r=0.69), 19$ of 20 (95\%; mean Rayleigh's $r=0.64$ ), and 17 of 19 (89\%; mean Rayleigh's $r=0.62$ ), respectively (Fig. $6 B)$. The decrease in the total number of cells recorded across sessions resulted from lost isolation of unit activity. In contrast to C57BL/6J HD cells, a greater percentage of tilted HD cells became nondirectional across sessions. For tilted mice, nine of nine cells
S1-S5

(100\%; mean Rayleigh's $r=0.53$ ) were directional during session 1 , and each successive recording session resulted in a lower percentage of cells remaining directional. For session 3, five of nine cells (56\%; mean Rayleigh's $r=0.39$ ) remained directional, and three of eight cells (38\%; mean Rayleigh's $r=0.34$ ) remained directional during session 5. Thus, HD cells in tilted mice showed reduced directionality across sessions within the same day relative to HD cells in C57BL/6J mice. Two simultaneously recorded HD cells from C57BL/6J and tilted mice are presented in Figure 9 to illustrate HD signal degradation in tilted mice across sequential sessions.

To determine whether the decreased directionality of HD cells in tilted mice was related to the amount of movement exhibited by the mouse during a recording session, we calculated the total distance traveled during sessions 1,3 , and 5 for C57BL/6J and tilted mice. These measures are plotted in Figure 6C. Although sessions 1 and 5 show less movement in tilted mice, a repeated-measures ANOVA indicated there was no significant difference between C57BL/6J and tilted mice in the amount of total movement across sessions $\left(F_{(1,16)}=2.154 ; p=0.16\right)$ or in the group $\times$ session interaction $\left(F_{(2,32)}=\right.$ 2.52; $p=0.096)$. Furthermore, we conducted a correlation analysis to determine whether total distance was associated with the Rayleigh's $r$ value. For C57BL/6J mice, total distance was not well correlated with Rayleigh's $r$ value during session $1(r=-0.028 ; p=0.92)$, session $3(r=0.144 ; p=$ $0.55)$, or session 5 ( $r=0.326 ; p=0.18)$. Similarly for tilted mice, total distance traveled was not well correlated with Rayleigh's $r$ values during session $1(r=0.019 ; p=0.97)$, session $3(r=$ $-0.146 ; p=0.72)$, or session $5(r=0.349 ; p=0.41)$. Thus, although differences in the amount of movement were observed between C57BL/6J and tilted mice, these differences did not predict the degree of the direction-specific firing of the cell.

In summary, the directional firing of C57BL/6J HD cells remained robust across recording sessions. Furthermore, most HD cells had a preferred firing direction that remained fairly consistent across standard recording sessions within the same day and across days. In contrast, most HD cells in tilted mice became nondirectional over the course of recording. For tilted mouse HD cells that remained directional across sessions, an increasing amount of variation was observed between the preferred direction established during session 1 and that of subsequent recording sessions.

\section{Dark/no cue sessions: C57BL/6J mice}

During session 4 (dark/no cue), the preferred direction for 11 of 19 HD cells (57.9\%, recorded in seven sessions) did not drift a large amount throughout the session. These cells are henceforth referred to as "stable" HD cells, and an example is depicted in Figure 10, $A$ and $B$. In all cases, simultaneously recorded HD cells showed similar amounts of drift in their preferred direction throughout the recording session, and we therefore used the 
mean of the individual drifts for statistical analyses. For three HD cells (two cells were recorded simultaneously), the preferred direction drifted CW at the beginning of the session and then drifted CCW later in the session. Although all three of these cells had greater drifts in their preferred direction than other stable HD cells, these cells were classified as stable because their activity was significantly directional (Rayleigh's $r>0.4$ ). For stable HD cells, the mean absolute drift in the preferred direction was $0.127 \pm 0.048 \%$ (range, $0.014-0.343 \%$ s).

To determine whether the tracking LEDs provided ambient illumination usable for navigation, we compared the stability of the preferred direction in C57BL/6J HD cells with that of previously reported HD cells recorded from blindfolded rats, which would not have been able to use any ambient illumination from the LEDs (Goodridge et al., 1998). From the firing rate $\times \mathrm{HD} \times$ time analysis, the mean drift of the preferred direction in blindfolded rats was $0.061 \pm 0.011 \%$ (range, $0.004-0.281^{\circ} / \mathrm{s}$ ) compared with $0.127^{\circ} / \mathrm{s}$ for mice. The small drift over time in stable mouse HD cells is thus similar to the drift observed in cells from blindfolded rats $\left(t_{(32)}=0.208 ; p=0.837\right)$. Consequently, the illumination provided by the tracking LEDs did not appear to facilitate the accuracy of directional perception in mice.

For 8 of 19 C57BL/6J HD cells (42.1\%, recorded in five sessions) recorded during darkness, the drift of the preferred direction was substantial. These cells are henceforth referred to as "unstable" HD cells. Note that all unstable HD cells were recorded from two mice, although stable HD cells were also recorded from both of these mice on different days (Table 3 ). The activity of these HD cells was not random, but instead the preferred firing direction appeared to drift in a constant direction across the mouse's multidirectional movements (Fig. 10C,D) (all unstable cells are depicted in supplemental Fig. S6, available at www.jneurosci.org as supplemental material). This constant drift is markedly different from the random bursts of "bursty" cells in tilted mice (described above). Unstable HD cells showed a mean drift in their preferred directions of $1.539 \pm$ $0.160 \%$ s (range, $1.084-1.892^{\circ} / \mathrm{s}$ ) (Fig. $10 E$ ). The drift in preferred direction of unstable HD cells suggests a lack of consistent perceived directional heading in the absence of visual information, and this lack of HD perception may reflect the absence of detected spatial cues during some recording sessions. This idea is further supported by the fact that all simultaneously recorded $\mathrm{HD}$ cells
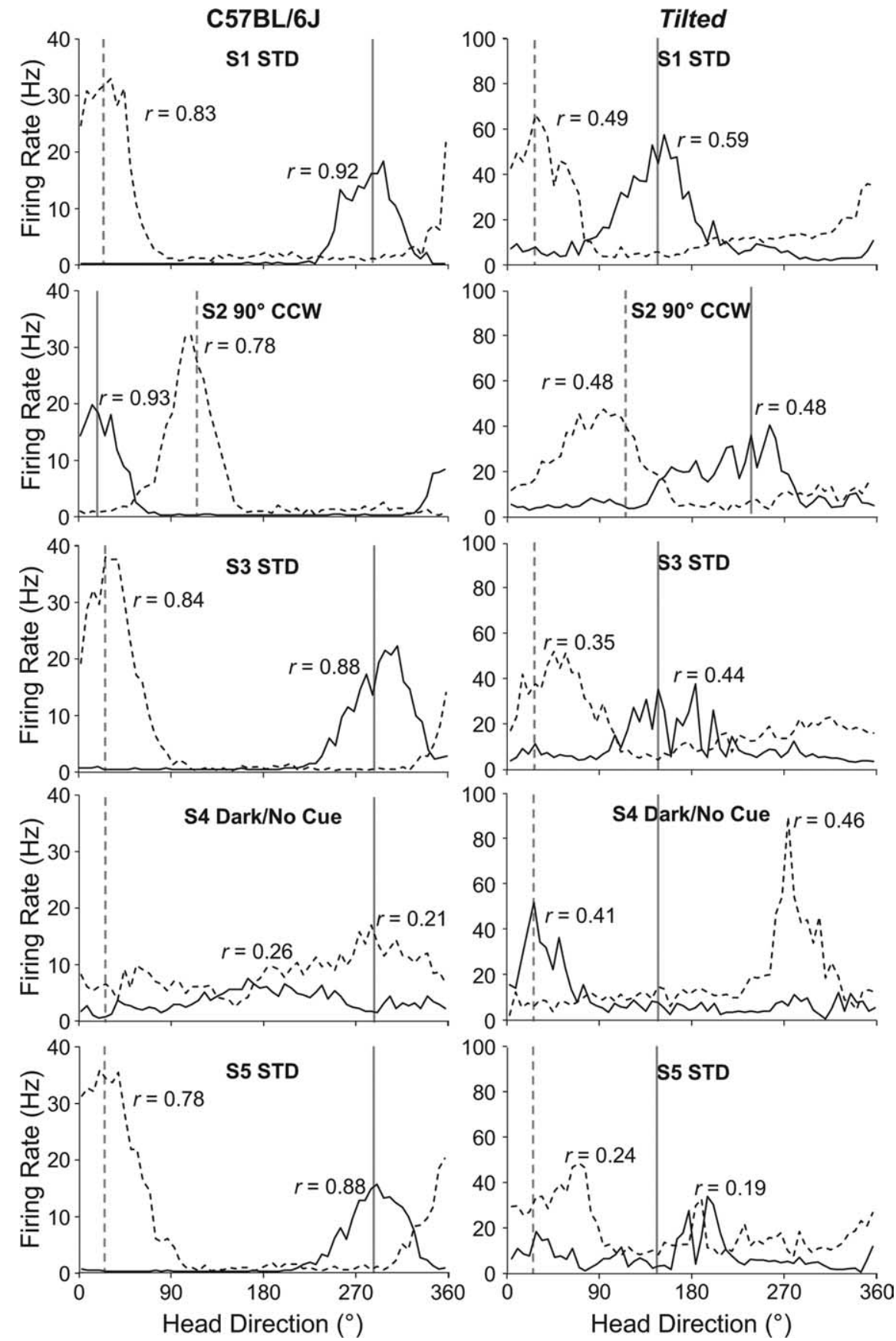

Figure 9. Loss of robust HD signal across trials in tilted mice. The preferred firing direction of each cell is indicated by vertical solid and dashed lines; Rayleigh's $r$ values are shown for all tuning curves. Left, C57BL/6J mouse: signals from two $\mathrm{HD}$ cells recorded simultaneously on different electrodes remained stable across lighted recording sessions. Cell 1 (solid) and cell 2 (dashed) showed robust directionality throughout standard session 1 (S1). In session 2 (S2), cell 1 shifted $96^{\circ}$ and cell 2 shifted $84^{\circ}$ after a $90^{\circ} \mathrm{CCW}$ rotation of the visual cue (vertical lines indicate $90^{\circ}$ shift relative to each cell's preferred direction in S1). In session 3 (S3), the preferred firing direction of both cells returned to the standard alignment, corresponding to replacement of the visual cue to the standard position. During session 4 (S4) in darkness, both HD cells became unstable, resulting in broad tuning curves with no well defined peak. In session 5 (S5), the cells regained their directional tuning, indicated by return of the preferred directions to the standard alignment. Note that in all sessions recorded during lighted conditions, the background firing rate remained low. Right, 0toconia-deficient tilted mouse: degradation of HD signal across recording sessions for two HD cells recorded simultaneously on different electrodes. In S1, the tuning curves of cell 1 (solid) and cell 2 (dashed) indicate a significant directional preference. In S2, the preferred direction of these HD cells shifted 96 and $66^{\circ}$, respectively, after a $90^{\circ}$ rotation of the visual cue, indicating visual information influenced the HD signal. The tuning curves of both cells became slightly broader during $\$ 3$ relative to $\$ 1$, indicating increased activity across a greater directional range. In the darkness/no cue session (S4), the preferred directions of both cells maintained the angular relationship to one another despite the absence of visual information. Unlike C57BL/6J HD cells, tuning curves of tilted HD cells showed decreasing directionality across recording sessions. All cell waveforms remained well isolated throughout the recording sessions. STD, Standard session under light conditions. 

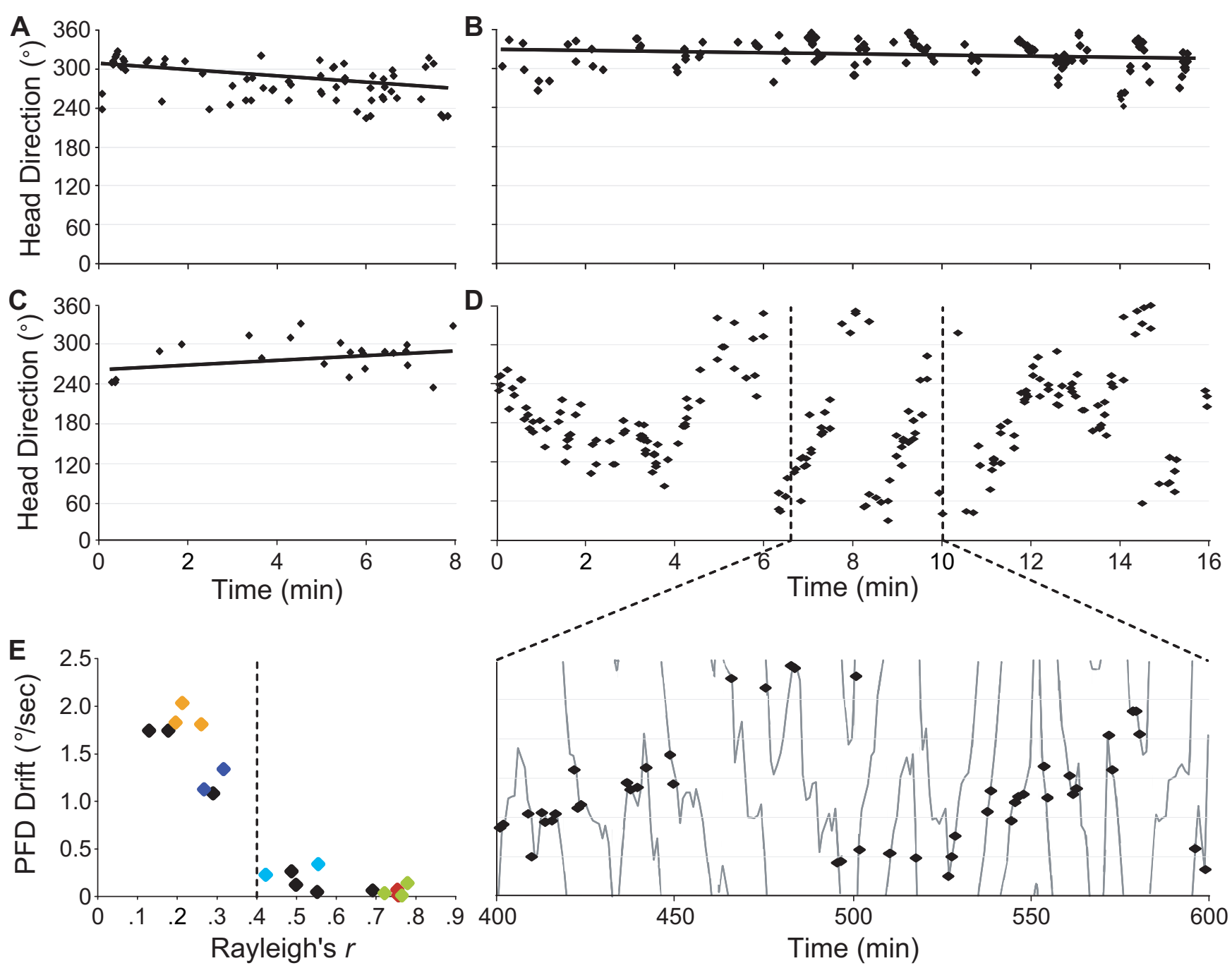

Figure 10. Firing rate $\times \mathrm{HD} \times$ time plot showing $(57 \mathrm{BL} / 6 \mathrm{~J} \mathrm{HD}$ cell stability characteristics during light and darkness. A linear slope, indicated by a black line, was fit to data from cells in which the preferred direction shifted $<360^{\circ}$ within the recording session. Cell $1(\boldsymbol{A}, \boldsymbol{B})$ showed an increased firing rate within a limited range of head directions throughout session 1 (standard, 8 min) and session 4 (darkness/no cue, 16 min), indicating HD cell stability during light and darkness. Cell $2(\boldsymbol{C}, \boldsymbol{D})$ showed an increased firing rate within a limited range of head directions throughout session 1 but failed to maintain directional tuning during darkness (session 4), indicating that this $\mathrm{HD}$ cell was unstable in the absence of visual cues. Inset in $\mathbf{D}$ includes depiction of actual head direction (solid line). Cells 1 and 2 were recorded from different animals. $E$, Preferred firing direction (PFD) drift for all HD cells recorded during the dark recording session. HD cell stability was indicated by significant directionality (Rayleigh's $r>0.40$ ) and showed a PFD drift of $<0.5^{\circ} / \mathrm{s}$. HD cells that failed to maintain directionality showed a PFD drift of $>0.5^{\circ} / \mathrm{s}$. Black points represent cells recorded individually; colored points represent simultaneously recorded cells and correspond to Figure 8 and supplemental Figure $\$ 6$ (available at www.jneurosci.org as supplemental material). Dashed line indicates significance criterion for directionality.

showed similar stability characteristics within any given recording session.

Alternatively, one possible cause for the instability of some HD cells in darkness is a greater distance traveled or greater number of head turns during the recording session. To examine this issue, we calculated the total distance traveled, as well as the number of complete revolutions in the CW and CCW directions for $\mathrm{HD}$ cells recorded for $16 \mathrm{~min}$ in the dark/no cue session. For two dark recording sessions during which two stable HD cells were recorded, the session was terminated after $8 \mathrm{~min}$; for these sessions, the distance traveled and number of head turns were multiplied by 2 to estimate the distance traveled and the number of head turns for a 16 min session. Overall, for 11 stable HD cells (recorded in eight sessions), the mean \pm SEM distance traveled was $410.36 \pm 21.58 \mathrm{~cm}$. The mean overall number of head turns was $40.57 \pm 2.51 \mathrm{CW}$ versus $38.88 \pm 2.15 \mathrm{CCW}$. For the eight HD cells (recorded in five sessions) that became unstable in darkness, the mean overall distance traveled was $509.12 \pm 75.53 \mathrm{~cm}$, and the mean number of head turns was $44.12 \pm 6.13 \mathrm{CW}$ and $40.99 \pm 5.69 \mathrm{CCW}$. For total distance and number of head turns, no difference was observed between stable and unstable HD cells $(p>0.05)$, suggesting that the large drift observed in unstable HD cells did not arise because of a greater distance traveled or a larger number of head turns.

\section{"Visual" versus "nonvisual" HD cells}

In rats, ADN HD cells typically remain stable in darkness over time intervals on the order of minutes (Blair and Sharp, 1995; Goodridge et al., 1998). The present results from C57BL/6J mice indicate that some HD cells become unstable in darkness. One possibility is that some HD cells in mice could be influenced primarily by visual afferents, whereas others are influenced primarily by vestibular afferents. However, if there are different HD cell subtypes within the ADN, there is no topological organization to them because both stable and unstable HD cells were recorded throughout the dorsoventral axis of ADN. If "visual" 
HD cells are influenced primarily by visual information, then these cells would (1) become unstable when visual information is not available and (2) show strong influence of visual cue rotation. Conversely, if "nonvisual" HD cells depend primarily on selfmovement information, then these cells should (1) remain stable whether or not visual information is present and (2) may show less influence of cue card rotation. To address these predictions, we evaluated the probability that visual HD cells (cells that responded well to cue card rotation) became unstable in darkness and that nonvisual HD cells remained stable in darkness. This analysis was conducted according to session; therefore, if more than one HD cell was recorded simultaneously, responses for both (or all three) HD cells were averaged to obtain a single value. Although not exclusive, these predictions were observed in the present study, in which 7 of $13(54 \%)$ visual HD cells became unstable in darkness and a greater percentage $(5$ of $5 ; 100 \%)$ of nonvisual HD cells remained stable in darkness $\left(\chi^{2}=4.41 ; p<\right.$ $0.05)$. Thus, consistent with the hypothesized predominant reliance of some HD cells on visual information, the HD cells that demonstrated good cue control in rotation experiments were more likely to become unstable in dark sessions than were cells that displayed poor cue control. However, a second prediction from the visual versus nonvisual hypothesis is that, when multiple HD cells are simultaneously recorded, a percentage of these cells should become unstable in darkness whereas others should remain directional. This prediction was not observed, because all simultaneously recorded HD cells either remained stable or became unstable during a given recording session, whether in light or darkness. Therefore, the most likely explanation for visual versus nonvisual dependence of some HD cell recording sessions is variation in the spatial information detected and/or perceived by the mouse across recording sessions.

\section{Tilted mice}

In tilted mice, only five HD cells had sufficiently stable preferred firing directions at the end of session 3 to enable assessment in the dark/no cue session. The preferred direction of four of these HD cells remained stable throughout session 4. Only one HD cell, which remained stable through session 3 , showed extreme instability during darkness and then regained directionality during session 5. For stable HD cells in tilted mice, the mean absolute value of the drift in preferred direction during darkness was $0.015 \pm 0.003 \%$ s (range, $0.009-0.021 \%$ ). The absolute value of preferred direction drift did not differ between C57BL/6J and tilted mice $\left(t_{(9)}=1.513 ; p=0.165\right)$. Tilted mice showed a higher percentage of HD cells that remained stable during darkness than did C57BL/6J mice. This greater percentage of stable cells may have resulted from a general reduced stability of HD cells in tilted mice; the HD cells that would have become unstable during darkness may have become unstable in light before assessment during darkness.

\section{Discussion}

The present study assessed the activity of HD cells in wild-type C57BL/6J and otoconia-deficient tilted mice. The HD signal in $\mathrm{C} 57 \mathrm{BL} / 6 \mathrm{~J}$ mice appeared similar in some ways to that of rats during lighted conditions, but the mouse HD signal was unstable almost half the time (42\%) during darkness. Furthermore, the signal provided by the otolith organs appears to provide an important component of the HD signal, indicated by a degraded HD signal in mice lacking otoconia. Although HD cells were found in the ADN of otoconia-deficient mice, several key features of ADN cell activity of tilted mice were distinct from that of C57BL/6J mice. First, fewer HD cells were found in tilted mice, and the ones that were identified had lower directionality scores than HD cells in C57BL/6J mice (Fig. 6). Second, whereas C57BL/6J HD cells showed a robust HD signal across recording sessions, most HD cells in tilted mice showed reduced directional tuning across sessions (Figs. 6, 9). Additionally, some ADN cells in tilted mice had firing properties characteristic of HD cells, but the directional headings at which the cell fired did not remain constant within each recording session (Figs. 4, 5). These cells, which were rarely observed in C57BL/6J mice, did not have a significant preferred firing direction but instead fired in bursts as the animal locomoted around the arena. These differences between the ADN cells of C57BL/6J and tilted mice indicate an important role of the otolith organs in directional perception.

\section{HD cells in mice}

Some properties of mouse HD cells appear similar to those of rats: (1) the tuning curves as plotted in a firing rate versus HD graph generally appear similar, (2) the preferred direction of an HD cell remains constant, despite the mouse's behavior or location within an arena, (3) the preferred direction of each HD cell can be controlled by rotation of a salient visual cue, (4) some HD cells maintain a preferred direction in darkness, and (5) no accommodation of spike amplitude was observed during bursts of HD cell activity. However, some notable differences were observed between the mouse and rat HD signal, and these differences are described below.

Compared with the rat HD signal, mouse HD cells have, on average, broader tuning curves. An increased breadth of the average tuning curve can occur when the preferred firing direction does not remain stable within a recording session. This possibility was observed in the present study, because mice showed greater variability in preferred firing direction through the standard recording session relative to rats. This increased variability may have been caused by the reduced visual acuity of mice relative to rats (Prusky et al., 2000), which possibly provided a less precise perception of visual cue location. Alternatively, slight instability of perceived HD may have been caused by the lack of velocity storage in mice (van Alphen et al., 2001). The velocity storage mechanism provides a prolonged representation of angular head velocity in central vestibular neurons and helps to stabilize gaze and perceived motion during angular head rotations (Raphan et al., 1979; Okada et al., 1999). Supportive of this suggestion, preliminary experiments in our laboratory with lesioned rats indicate that stability of the HD signal over time relies on an intact velocity storage mechanism (Bassett and Taube, 2005).

Another factor that may have influenced the accuracy of the HD signal is attentional demand. Hippocampal spatial representation in mice appears to depend on cognitive effort required for task performance, with place cell instability occurring during tasks with low attentional demands (Kentros et al., 2004). In the present experiment, untrained mice locomoted freely around an arena with no specific goal location, a task with presumably low attentional demand. Despite this low attentional demand, the HD signal remained directional during lighted conditions, indicating that HD signal integrity may not predict the stability of hippocampal place cell activity. Nevertheless, this directional signal appears to depend on visual information, because some HD cells become unstable in darkness. Mice may be less likely to keep track of their spatial orientation during tasks in which both the visual and attentional demand components are missing. In the case of a high-demand task with no visual information, such as path integration, the HD signal may have remained stable for a 
greater percentage of HD cells. Consistent with this view, mice are able to perform path integration tasks quite accurately, even in three dimensions (Bardunias and Jander, 2000; Gorny et al., 2002). However, if greater attentional demand does not facilitate a stable HD signal during darkness, path integration could be impaired approximately half of the time. It would be interesting to determine whether the absence of a stable HD signal in darkness would translate into impaired performance on a spatial task in darkness.

\section{Otolithic involvement in the HD signal}

The otolith organs sense linear acceleration and head tilt, whereas the semicircular canals sense angular acceleration. Because the horizontal canals are activated in a similar manner when a subject turns their head in the yaw plane while in an upright position and when the subject makes the same head movement while in a supine position, an additional signal is necessary to differentiate the two movements with respect to the external world. These head movements can be differentiated if a signal containing information about the subject's orientation with respect to gravity is integrated with the angular motion signal (Raphan and Cohen, 1988). Activity of the otoliths would provide this necessary information, and recent work has postulated that these vestibular signals are integrated in the nodulus and uvula of the cerebellum to provide an accurate representation of head movement through space (Yakusheva et al., 2007). These cerebellar areas in turn project back to the vestibular nuclei and the resultant angular head velocity (AHV) signal is then projected to the dorsal tegmental nucleus (DTN) via the nucleus prepositus (Liu et al., 1984) and supragenual nucleus (Biazoli et al., 2006). In the DTN, the vast majority of cells respond to the velocity of head turn within the yaw plane, and this AHV signal provides a necessary component of the HD signal, possibly by controlling the ATI of HD cells (Bassett and Taube, 2001; Sharp et al., 2001a,b; Bassett et al., 2007). However, in the present study, the ATI of HD cells in tilted mice did not differ from C57BL/6J mice, suggesting that, if the AHV signal is involved in control of the ATI, this function of AHV perception does not depend on gravity perception. Furthermore, because passive head turns do not disrupt the ATI in HD cells (Bassett et al., 2005), motor commands do not appear to be required for the ATI. Thus, signals from the semicircular canals appear to provide the vestibular contribution to the ATI of ADN HD cells.

Additional evidence for otolithic involvement in the HD signal can be inferred from a previous study in which HD cell activity became markedly degraded, or was lost altogether, as rats locomoted in an inverted position (Calton and Taube, 2005). In this task, direction-specific firing was attenuated when the rats were inverted despite (1) an intact semicircular canal system that sensed angular motion, (2) repeated exposure to familiar room cues that could have been used as visual landmarks, and (3) extensive training and experience on the task. Together with the present results, HD signal degradation in rats during inverted navigation may be attributed to the absence of a familiar otolith signal. Although both rats and mice are agile climbers, mice spend considerably more time than rats hanging from the ceiling of their home cages (our unpublished observations). However, the navigational content of this inversion remains unknown. For this reason it would be interesting to record directional activity in species, such as squirrels, that spend considerably more time locomoting while in inverted positions. An alternative explanation for HD signal degradation during inversion is an altered visual environment. This possibility is unlikely, however, because HD cells remain relatively stable when rats are blindfolded (Goodridge et al., 1998) and movement of rats to a novel environment typically results in the shifting of HD cell preferred firing directions rather than signal degradation. Nevertheless, alteration of the otolith signal differs from removal of the otolith signal, which presumably occurs in animals with congenital otoconia deficiency. It remains possible that tilted mice have developed a compensatory mechanism that facilitates HD signals despite the lack of gravity perception, and this mechanism is not present in rats during brief periods ( $<1 \mathrm{~min}$ ) of inverted navigation.

A remaining issue regarding $\mathrm{HD}$ cell activity in otoconiadeficient mice is why an HD cell would maintain a robust representation of HD for several minutes during the first standard recording session on any particular day, only to lose this robust directionality within minutes and remain nondirectional through the second day of assessment. One possibility is that this signal degradation was induced by the experimental procedures. After introduction to the arena, the mouse perceived environmental features and developed a robust HD representation. At the end of each recording session, the mouse was handled by the researcher and disoriented before reintroduction to the arena. Despite visual features of the arena remaining unchanged, the mouse undoubtedly perceived that it had been handled and/or moved by the researcher. Although visual cues typically take precedence over movement cues for control of HD cells (Goodridge and Taube, 1995), the relative location or appearance of visual cues may appear somewhat unstable without a strong perception of the subjective visual vertical, which depends on an interaction between visual and otolith signals (Mittelstaedt, 1986; Bronstein, 1999). Perceived visual cue instability, along with impaired gravity detection, may have led to the observed HD signal degradation, which increased with subsequent trials. Alternatively, handling between sessions may have caused disorientation that persisted through subsequent recording sessions and resulted in HD signal degradation.

\section{Summary and conclusions}

The present study provides evidence that the HD signal of mice is similar in many ways to that of rats. The otolith organs may contribute a spatial reference to the perception of body orientation relative to the environment, and this representation of a subjective vertical may facilitate a robust perception of HD. Concordantly, the HD signal of wild-type mice remained relatively stable and robust across standard and rotation trials and sometimes remained stable during darkness. In tilted mice, however, HD cells that remained directional for the duration of a single recording session often lost directionality across subsequent recording sessions. Along with previous studies, these results indicate the HD signal depends on information from the visual system, the semicircular canals, and the otolith organs. Although additional experimentation is necessary to address the otolith/ canal interaction involved in HD perception, the present experiment provides the first conclusive evidence that the otolith organs are important for maintenance of a robust HD signal.

\section{References}

Adrian ED (1943) Discharges from vestibular receptors in the cat. J Physiol 101:389-407.

Angelaki DE, Dickman JD (2003) Gravity or translation: central processing of vestibular signals to detect motion or tilt. J Vestib Res 13:245-253.

Angelaki DE, McHenry MQ, Dickman JD, Newlands SD, Hess BJ (1999) Computation of inertial motion: neural strategies to resolve ambiguous otolith information. J Neurosci 19:316-327. 
Bardunias PM, Jander R (2000) Three dimensional path integration in the house mouse (Mus domestica). Naturwissenschaften 87:532-534.

Bassett JP, Taube JS (2001) Neural correlates for angular head velocity in the rat dorsal tegmental nucleus. J Neurosci 21:5740-5751.

Bassett JP, Taube JS (2005) The velocity storage integrator contributes to stable head direction representations. Soc Neurosci Abstr 31:392.1.

Bassett JP, Zugaro MB, Muir GM, Golob EJ, Muller RU, Taube JS (2005) Passive movements of the head do not abolish anticipatory firing properties of head direction cells. J Neurophysiol 93:1304-1316.

Bassett JP, Tullman ML, Taube JS (2007) Lesions of the tegmentomammillary circuit in the head direction system disrupt the head direction signal in the anterior thalamus. J Neurosci 27:7564-7577.

Batschelet E (1981) Circular statistics in biology. New York: Academic.

Biazoli CE Jr, Goto M, Campos AM, Canteras NS (2006) The supragenual nucleus: a putative relay station for ascending vestibular signs to head direction cells. Brain Res 1094:138-148.

Blair HT, Sharp PE (1995) Anticipatory head direction signals in anterior thalamus: evidence for a thalamocortical circuit that integrates angular head motion to compute head direction. J Neurosci 15:6260-6270.

Blair HT, Lipscomb BW, Sharp PE (1997) Anticipatory time intervals of head-direction cells in the anterior thalamus of the rat: implications for path integration in the head-direction circuit. J Neurophysiol 78:145-159.

Brandt T, Schautzer F, Hamilton DA, Brüning R, Markowitsch HJ, Kalla R, Darlington C, Smith P, Strupp M (2005) Vestibular loss causes hippocampal atrophy and impaired spatial memory in humans. Brain 128:2732-2741.

Bronstein AM (1999) The interaction of otolith and proprioceptive information in the perception of verticality. The effects of labyrinthine and CNS disease. Ann N Y Acad Sci 871:324-333.

Brown JE, Carey JP, Minor LB, Taube JS (2006) Chinchilla horizontal semicircular canals are necessary but not sufficient for normal head-direction cell activity. Soc Neurosci Abstr 32:68.25.

Calton JL, Taube JS (2005) Degradation of head direction cell activity during inverted locomotion. J Neurosci 25:2420-2428.

Fernández C, Goldberg JM (1976a) Physiology of peripheral neurons innervating otolith organs of the squirrel monkey. I. Response to static tilts and to long-duration centrifugal force. J Neurophysiol 39:970-984.

Fernández C, Goldberg JM (1976b) Physiology of peripheral neurons innervating otolith organs of the squirrel monkey. II. Directional selectivity and force-response relations. J Neurophysiol 39:985-995.

Fernández C, Goldberg JM (1976c) Physiology of peripheral neurons innervating otolith organs of the squirrel monkey. III. Response dynamics. J Neurophysiol 39:996-1008.

Fernandez C, Goldberg JM, Abend WK (1972) Response to static tilts of peripheral neurons innervating otolith organs of the squirrel monkey. J Neurophysiol 35:978-987.

Goodridge JP, Taube JS (1995) Preferential use of the landmark navigational system by head direction cells in rats. Behav Neurosci 109:49-61.

Goodridge JP, Dudchenko PA, Worboys KA, Golob EJ, Taube JS (1998) Cue control and head direction cells. Behav Neurosci 112:749-761.

Gorny JH, Gorny B, Wallace DG, Whishaw IQ (2002) Fimbria-fornix lesions disrupt the dead reckoning (homing) component of exploratory behavior in mice. Learn Mem 9:387-394.

Kentros CG, Agnihotri NT, Streater S, Hawkins RD, Kandel ER (2004) Increased attention to spatial context increases both place field stability and spatial memory. Neuron 42:283-295.

Khabbaz A, Fee MS, Tsien JZ, Tank DW (2000) A compact convergingelectrode microdrive for recording head direction cells in mice. Soc Neurosci Abstr 26:367.20.

Khabbaz AN, Tank DW (2004) Recording head direction cells in head fixed mice. Soc Neurosci Abstr 30:667.8.

Kubie JL (1984) A driveable bundle of microwires for collecting single-unit data from freely-moving rats. Physiol Behav 32:115-118.

Lane P (1986) Tilted (tlt). Mouse News Lett 75:28.

Liu R, Chang L, Wickern G (1984) The dorsal tegmental nucleus: an axoplasmic transport study. Brain Res 310:123-132.

Mittelstaedt H (1986) The subjective vertical as a function of visual and extraretinal cues. Acta Psychol (Amst) 63:63-85.
Muir GM, Carey JP, Hirvonen TP, Minor LB, Taube JS (2004) Head direction cell activity is unstable following plugging of the semicircular canals in the freely-moving chinchilla. Soc Neurosci Abstr 30:868.11.

Okada T, Grunfeld E, Shallo-Hoffmann J, Bronstein AM (1999) Vestibular perception of angular velocity in normal subjects and in patients with congenital nystagmus. Brain 122:1293-1303.

Ornitz DM, Bohne BA, Thalmann I, Harding GW, Thalmann R (1998) Otoconial agenesis in tilted mutant mice. Hear Res 122:60-70.

Ossenkopp KP, Prkacin A, Hargreaves EL (1990) Sodium arsanilateinduced vestibular dysfunction in rats: effects on open-field behavior and spontaneous activity in the automated digiscan monitoring system. Pharmacol Biochem Behav 36:875-881.

Prusky GT, West PW, Douglas RM (2000) Behavioral assessment of visual acuity in mice and rats. Vision Res 40:2201-2209.

Raphan T, Cohen B (1988) Organizational principles of velocity storage in three dimensions. The effect of gravity on cross-coupling of optokinetic after-nystagmus. Ann N Y Acad Sci 545:74-92.

Raphan T, Matsuo V, Cohen B (1979) Velocity storage in the vestibuloocular reflex arc (VOR). Exp Brain Res 35:229-248.

Schautzer F, Hamilton D, Kalla R, Strupp M, Brandt T (2003) Spatial memory deficits in patients with chronic bilateral vestibular failure. Ann N Y Acad Sci 1004:316-324.

Sharp PE, Blair HT, Cho J (2001a) The anatomical and computational basis of the rat head-direction cell signal. Trends Neurosci 24:289-294.

Sharp PE, Tinkelman A, Cho J (2001b) Angular velocity and head direction signals recorded from the dorsal tegmental nucleus of gudden in the rat: implications for path integration in the head direction cell circuit. Behav Neurosci 115:571-588.

Stackman RW, Herbert AM (2002) Rats with lesions of the vestibular system require a visual landmark for spatial navigation. Behav Brain Res 128:27-40.

Stackman RW, Taube JS (1997) Firing properties of head direction cells in the rat anterior thalamic nucleus: dependence on vestibular input. J Neurosci 17:4349-4358.

Stackman RW, Taube JS (1998) Firing properties of rat lateral mammillary single units: head direction, head pitch, and angular head velocity. J Neurosci 18:9020-9037.

Stackman RW, Clark AS, Taube JS (2002) Hippocampal spatial representations require vestibular input. Hippocampus 12:291-303.

Tait J, McNally WJ (1934) Some features of the action of the utricular maculae (and of the associated action of the semicircular canals) of the frog. Philos Trans R Soc Lond B Biol Sci 224:241-286.

Taube JS (1995) Head direction cells recorded in the anterior thalamic nuclei of freely moving rats. J Neurosci 15:70-86.

Taube JS (2007) The head direction signal: origins and sensory-motor integration. Annu Rev Neurosci 30:181-207.

Taube JS, Muller RU (1998) Comparisons of head direction cell activity in the postsubiculum and anterior thalamus of freely moving rats. Hippocampus 8:87-108.

Taube JS, Muller RU, Ranck JB Jr (1990a) Head-direction cells recorded from the postsubiculum in freely moving rats. I. Description and quantitative analysis. J Neurosci 10:420-435.

Taube JS, Muller RU, Ranck JB Jr (1990b) Head-direction cells recorded from the postsubiculum in freely moving rats. II. Effects of environmental manipulations. J Neurosci 10:436-447.

van Alphen AM, Stahl JS, De Zeeuw CI (2001) The dynamic characteristics of the mouse horizontal vestibulo-ocular and optokinetic response. Brain Res 890:296-305.

Wallace DG, Hines DJ, Pellis SM, Whishaw IQ (2002) Vestibular information is required for dead reckoning in the rat. J Neurosci 22:10009-10017.

Yakusheva TA, Shaikh AG, Green AM, Blazquez PM, Dickman JD, Angelaki DE (2007) Purkinje cells in posterior cerebellar vermis encode motion in an inertial reference frame. Neuron 54:973-985.

Yoganarasimha D, Knierim JJ (2005) Coupling between place cells and head direction cells during relative translations and rotations of distal landmarks. Exp Brain Res 160:344-359.

Zhang K (1996) Representation of spatial orientation by the intrinsic dynamics of the head-direction cell ensemble: a theory. J Neurosci 16:21122126. 